\title{
Origin and evolutionary landscape of Nr2f transcription factors across Metazoa
}

\author{
Ugo Coppola ${ }^{1}$, Joshua S. Waxman $\oplus^{1,2 *}$ \\ 1 Molecular Cardiovascular Biology Division and Heart Institute, Cincinnati Children's Research Foundation, \\ Cincinnati, Ohio, United States of America, 2 Department of Pediatrics, University of Cincinnati College of \\ Medicine, Cincinnati, Ohio, United States of America \\ * joshua.waxman@cchmc.org
}

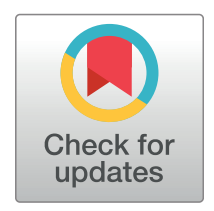

\section{Gopenaccess}

Citation: Coppola U, Waxman JS (2021) Origin and evolutionary landscape of Nr2ftranscription factors across Metazoa. PLOS ONE 16(11): e0254282. https://doi.org/10.1371/journal.pone.0254282

Editor: Michael Schubert, Laboratoire de Biologie du Développement de Villefranche-sur-Mer, FRANCE

Received: June 2, 2021

Accepted: November 7, 2021

Published: November 22, 2021

Peer Review History: PLOS recognizes the benefits of transparency in the peer review process; therefore, we enable the publication of all of the content of peer review and author responses alongside final, published articles. The editorial history of this article is available here: https://doi.org/10.1371/journal.pone.0254282

Copyright: @ 2021 Coppola, Waxman. This is an open access article distributed under the terms of the Creative Commons Attribution License, which permits unrestricted use, distribution, and reproduction in any medium, provided the original author and source are credited.

Data Availability Statement: All relevant data are within the manuscript and its Supporting information files.

Funding: Work in the manuscript was supported by National Institutes of Health (nih.gov) grants

\section{Abstract}

\section{Background}

Nuclear Receptor Subfamily 2 Group F (Nr2f) orphan nuclear hormone transcription factors (TFs) are fundamental regulators of many developmental processes in invertebrates and vertebrates. Despite the importance of these TFs throughout metazoan development, previous work has not clearly outlined their evolutionary history.

\section{Results}

We integrated molecular phylogeny with comparisons of intron/exon structure, domain architecture, and syntenic conservation to define critical evolutionary events that distinguish the Nr2f gene family in Metazoa. Our data indicate that a single ancestral eumetazoan Nr2f gene predated six main Bilateria subfamilies, which include single Nr2f homologs, here referred to as $N r 2 f 1 / 2 / 5 / 6$, that are present in invertebrate protostomes and deuterostomes, $\mathrm{Nr} 2 f 1 / 2$ homologs in agnathans, and Nr2f1, Nr2f2, Nr2f5, and Nr2f6 orthologs that are found in gnathostomes. Four cnidarian Nr2f1/2/5/6 and three agnathan Nr2f1/2 members are each due to independent expansions, while the vertebrate $\mathrm{Nr} 2 f 1 / \mathrm{Nr} 2 f 2$ and $\mathrm{Nr} 2 f 5 / \mathrm{Nr} 2 f 6$ members each form paralogous groups that arose from the established series of wholegenome duplications (WGDs). Nr2f6 members are the most divergent Nr2f subfamily in gnathostomes. Interestingly, in contrast to the other gnathostome Nr2f subfamilies, Nr2f5 has been independently lost in numerous vertebrate lineages. Furthermore, our analysis shows there are differential expansions and losses of Nr2f genes in teleosts following their additional rounds of WGDs.

\section{Conclusion}

Overall, our analysis of Nr2f gene evolution helps to reveal the origins and previously unrecognized relationships of this ancient TF family, which may allow for greater insights into the conservation of Nr2f functions that shape Metazoan body plans. 
R01 HL141186 and R01 HL137766 to JSW and by American Heart Association (heart.org) postdoctoral fellowship 831018 to UC. The funders had no role in study design, data collection and analysis, decision to publish, or preparation of the manuscript.

Competing interests: The authors have declared that no competing interests exist.

\section{Introduction}

Nuclear hormone receptors (NRs) form a large, ancient superfamily of transcription factors (TFs) found in all Metazoa [1]. While NR functions are often dictated by interactions with specific ligands, including steroids, thyroid hormones, and retinoids [2, 3], the ligands for many NRs, called orphan NRs, are still not known [4]. Nuclear Receptor Subfamily 2 Group F Members ( $\mathrm{Nr} 2 \mathrm{fs}$ ), initially named Chicken ovalbumin upstream promoter-transcription factors (Coup-TFs) due to their ability to bind the COUP element of the ovalbumin gene [5-7], are some of the most highly studied orphan NRs. Despite an overall expansion of the NR superfamily [1, 2], invertebrate phyla appear to have predominantly retained a single $N r 2 f$ gene. Only one $\mathrm{Nr} 2 \mathrm{f}$ member is present in the protostome Drosophila melanogaster (fly), earlybranching deuterostome Strongylocentrotus purpuratus (sea urchin) [8, 9], and invertebrate chordates Branchiostoma floridae (amphioxus) and Ciona robusta (sea squirt) [10, 11]. However, the number of $\mathrm{Nr} f$ genes in early-branching metazoans is presently less clear. In cnidarians, one $N r 2 f$ has been reported in Hydractinia echinata [12, 13], while multiple have been reported in Nematostella and Hydra vulgaris [14, 15]. In contrast to most invertebrates, vertebrates have exhibited a significant expansion of the Nr2f family, with gnathostomes having multiple $N r 2 f$ genes. Furthermore, teleosts possess additional Nr2f Ohnologs (duplicates originating from whole-genome duplication (WGD)) [16], most likely reflecting the additional WGDs that have occurred in the teleost lineage [17, 18].

$\mathrm{Nr} 2 \mathrm{f}$ proteins are highly conserved at the sequence level throughout Metazoa [19]. From the $\mathrm{N}$-terminus to the C-terminus, all Nr2f proteins have six domains (Fig 1): an A/B domain, which contains the activating function- $1(\mathrm{AF}-1)$ domain; the $\mathrm{C}$ domain, which contains the DNA-binding domain (DBD); the D domain (a linker); the $\mathrm{E}$ domain, which is comprised of the ligand-binding domain (LBD) and an AF-2 domain; the F domain (C-terminal) [20]. While the $\mathrm{A} / \mathrm{B}$ domains are the most divergent in sequence, strikingly, the DBDs and LBDs of $\mathrm{Nr} 2 \mathrm{f}$ members even from distantly related species (e.g. fly, sea urchin, frog, zebrafish, mouse, and human) are $94 \%$ identical [21]. The extremely high degree of conservation among several species implies the preservation of critical roles for $\mathrm{Nr} 2 \mathrm{f}$ in development and differentiation [21, 22]. Moreover, requirements for $N r 2 f$ genes have been found in organs of all three germ layers during embryogenesis [14, 22]. For instance, the Drosophila Nr2f homolog, called seven $u p(s v p)$, is required for retinal, dorsal vessel, and liver development [23, 24]. Furthermore, $\mathrm{Nr} 2 \mathrm{f}$ TFs in vertebrates appear to both have acquired diverse and retained redundant functions. For instance, in mice, $N r 2 f 1$ is predominantly required for neural development with a role in regulation of premigratory and migratory neural crest cells in the developing hindbrain $[25,26]$. However, the mouse $N r 2 f 2$ gene is required for differentiation of mesodermal derivatives, including atrial cardiomyocytes of the heart and venous endothelial cells [22, 27, 28]. An example of redundancy is zebrafish $n r 2 f 1 a$ and $n r 2 f 2$, which are both required for proper ventricular cardiomyocyte and cranial muscle specification [29].

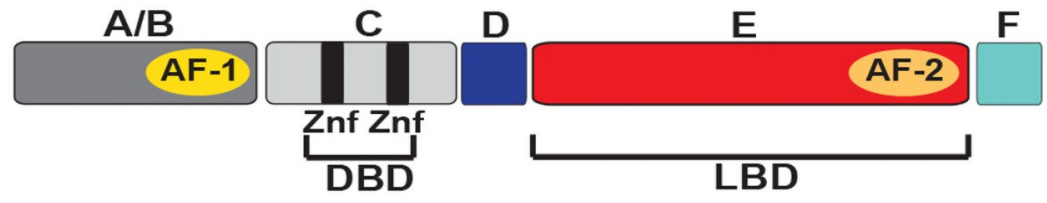

Fig 1. Schematic of conserved domain architecture of Nr2f TFs. A/B (N-terminal variable domain with transactivating AF-1 domain), C (DBD, which contains two Zinc finger (Znf) motifs), D (a linker domain), E (LBD plus transactivating AF-2 domain), and F (C-terminal).

https://doi.org/10.1371/journal.pone.0254282.g001 
While Nr2f proteins were initially identified as transcriptional activators of chicken ovalbumin gene [5], they have since been shown to function directly as both transcriptional activators and repressors in several developmental contexts [22, 30, 31]. Nr2fs can bind a range of different response elements [32-34] and in signaling reporter assays can compete with and inhibit retinoic acid receptors [35]. In vivo they bind numerous targets that reflect their various requirements in the specific tissues. For instance, $N r 2 f 1 \mathrm{KO}$ mice also have inner ear defects [36]. In the mouse inner ear, direct targets of $\mathrm{Nr} 2 \mathrm{f} 1$ include fatty acid binding protein 7 (FABP7), cellular retinoic acid binding protein 1 (CRABP1) [37], microRNA-140 (mi-R140), and Krüppel-like 9 (Klf9) [37, 38]. In adipogenesis, $\mathrm{Nr} 2 \mathrm{f} 2$ directly represses peroxisome proliferator-activated receptor $\gamma$ (PPAR $\gamma$ ) downstream of canonical Wnt/ $\beta$-catenin signaling [39]. In the mammalian heart, $\mathrm{Nr} 2 \mathrm{f} 2$ is thought to directly orchestrate a regulatory network that facilitates atrial cardiomyocyte identity through concurrently promoting $T b x 5$ and repressing Irx4 and Hey2, the latter of which promote ventricular cardiomyocyte identity [40]. Thus, $\mathrm{Nr} 2 \mathrm{fs}$ can activate and repress a range of direct targets related to their functions in specific tissues.

Despite the conservation and clear importance of this gene family to numerous developmental processes in Metazoa, we still do not completely understand the evolution of Nr2f TFs. Here, we investigated $\mathrm{Nr} 2 \mathrm{f}$ family evolution through a combination of phylogenetic, domain architecture, intron/exon structure, and genomic synteny analyses. Our data show that the single $N r 2 f$ gene found in placozoans, represents the ancestral $N r 2 f$ to those found in cnidarians, protostomes, and deuterostomes. Importantly, a single $\mathrm{Nr} 2 \mathrm{f}$ homolog, which we have named $\mathrm{Nr} 2 f 1 / 2 / 5 / 6$, is present in the majority of invertebrates, while most vertebrate genomes contain $N r 2 f 1, N r 2 f 2, N r 2 f 5$, and Nr2f6 orthologs, which are derived from established rounds of WGDs [41, 42]. Interestingly, the invertebrate $N r 2 f 1 / 2 / 5 / 6$ and agnathan $N r 2 f 1 / 2$ homologs have retained the greatest similarity with vertebrate $N r 2 f 1$ and $N r 2 f 2$ paralogs. With respect to the vertebrate $N r 2 f 5$ and $N r 2 f 6$ paralogs, $N r 2 f 5$ genes have been independently lost in some cartilaginous fish and amniote lineages, while the $N r 2 f 6$ subfamily is the most divergent with respect to sequence and genomic structure. Overall, our data clarify the relationships among $N r 2 f$ genes within Metazoa and define the expansion, divergence, and independent loss of extant $N r 2 f$ genes in vertebrates, which will allow us to make meaningful inferences about the conserved developmental functions of this family that have helped mold animal body plans.

\section{Results}

\section{Phylogenetic reconstruction of $\mathrm{Nr} 2 \mathrm{f}$ evolution in animals}

Although previous work has investigated the homology of some Nr2fs within metazoans, these analyses were primarily focused on their relationship to other NRs and were limited by the comparatively little genomic information at the time $[1,3,14,43,44]$. Therefore, the relatively few Nr2f family members examined in the previous analysis did not provide a specific and detailed understanding of Nr2f evolution. To garner a better understanding of how the Nr2f family has evolved in animals, we performed a phylogenetic analysis using $153 \mathrm{Nr} 2 \mathrm{f}$ proteins with representatives from placozoans to mammals (Fig 2; S1 File). Early-branching metazoan models Amphimedon queenslandica (sponge) and Mnemiopsis leidyi (ctenophore) were not included, as we did not find putative $\mathrm{Nr} 2 \mathrm{f}$ orthologs based on current databases, consistent with published phylogenetic studies of the NR superfamily $[13,15]$. The placozoan Trichoplax adhaerens $\mathrm{Nr} 2 \mathrm{f}$, which was previously shown to cluster with vertebrate $\mathrm{Nr} 2 \mathrm{fs}$ in phylogenetic analyses [45], was used as the outgroup in a maximum-likelihood (ML) phylogenetic tree. Protein sequences from groups that caused long branch artifacts due to significant divergence were not included in the phylogenetic trees (S2 File). This phylogenetic analysis provided 


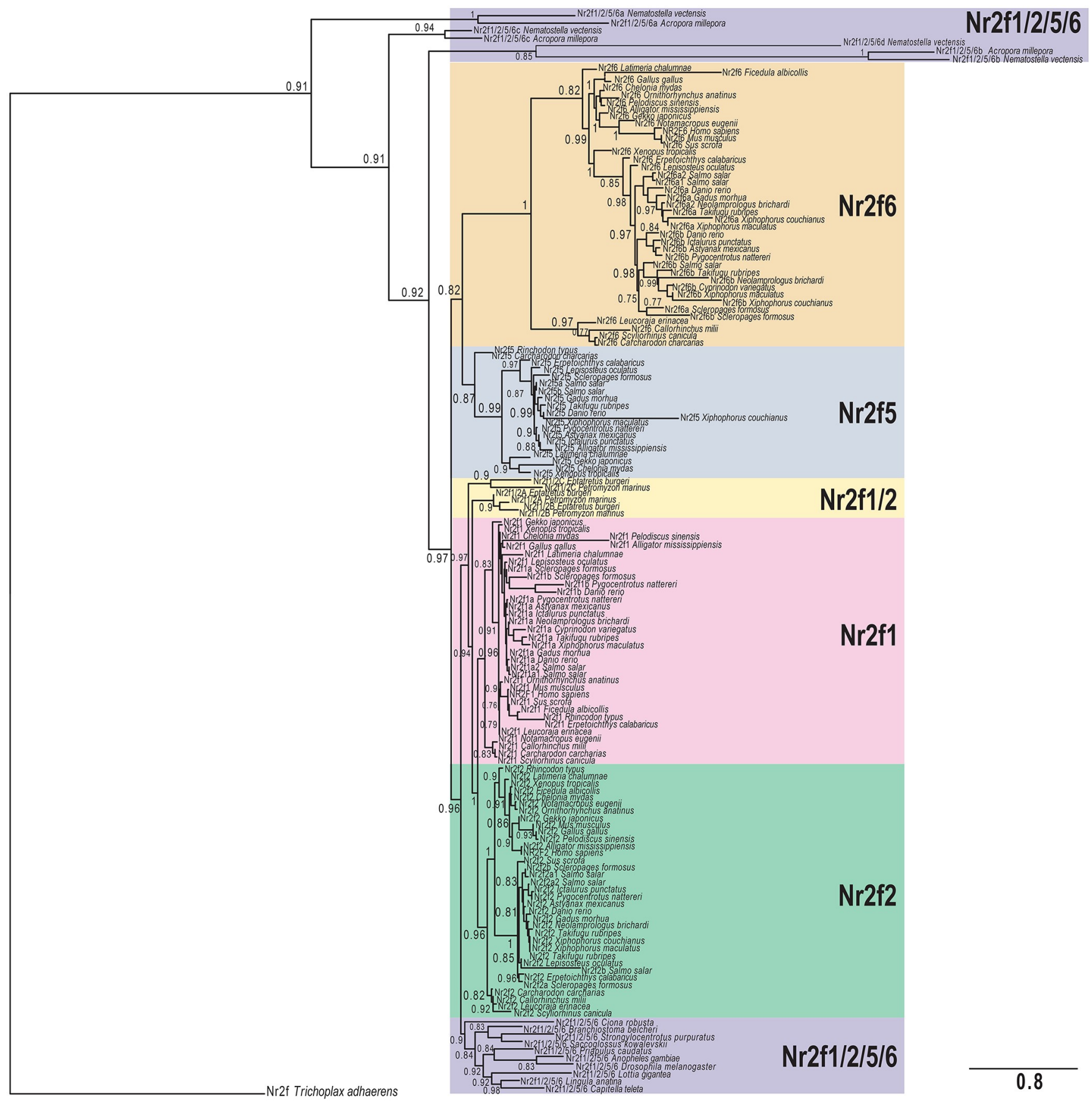

Fig 2. Evolutionary reconstruction of Nr2f TFs in metazoans. Phylogenetic tree of Nr2f members demonstrate the existence of six protein classes: Nr2f1/2/ 5/6 (violet box), Nr2f1/2 (yellow box), Nr2f1 (pink box), Nr2f2 (green box), Nr2f5 (blue box), Nr2f6 (orange box). The placozoan Trichoplax adhaerens Nr2f was used as the outgroup. Values at the branches indicate replicates obtained using the aLRT method.

https://doi.org/10.1371/journal.pone.0254282.g002

evidence for the existence of distinct Nr2f subfamilies (Fig 2). Moreover, the same relationships were also supported using a Bayesian model selection (S1 Fig). Present information allowed us to identify four $\mathrm{Nr2fs}$ in the cnidaria Nematostella vectensis and Acropora millepora, three in Hydra vulgaris, and one for Hydractinia echinata. However, while identifiable as $\mathrm{Nr} 2 \mathrm{fs}$, an $A$. millepora, the $H$. vulgaris, and the H. echinata $\mathrm{Nr} 2$ fs caused long-branch artifacts and were 
consequently excluded (S2 File). Interestingly, the tree incorporating the $N$. vectensis and remaining A. millepora $\mathrm{Nr} 2 \mathrm{f}$ members, which we now call Nr2f1/2/5/6a-d based on their relationship to Bilateria $\mathrm{Nr} 2 \mathrm{fs}$, were found at the base of the eumetazoan Nr2f proteins and are likely the result of gene duplications within cnidaria [15] (Fig 2). The protostome and deuterostome $N r 2 f$ sequences clustered into six subfamilies, which we have called $N r 2 f 1 / 2 / 5 / 6, N r 2 f 1 /$ 2, $N r 2 f 1, N r 2 f 2, N r 2 f 5$, and $N r 2 f 6$. Single $N r 2 f 1 / 2 / 5 / 6$ subfamily genes, which are highly conserved, yet evolutionary divergent from the $\mathrm{Nr} 2 f 1 / 2 / 5 / 6$ genes present in early-branching eumetazoa, were found in invertebrate protostomes, invertebrate deuterostomes (hemichordates, echinoderms), and invertebrate chordates (amphioxus, tunicates). An older nomenclature proposal suggested that the Drosophila Nr2f (svp) should be designated Nr2f3 [19], implying the other invertebrate Nr2fs should follow this nomenclature. However, this designation seems to obfuscate the homology of these genes revealed here and imply a different evolutionary relationship, as there is no distinct Nr2f3 subfamily. Thus, we propose using Nr2f1/2/5/ 6 or in the future potentially just $N r 2 f$ for the early-branching eumetazoan and invertebrate $N r 2 f$ genes. We have used $N r 2 f 1 / 2 / 5 / 6$ in this manuscript to refer to the invertebrate $N r 2 f s$ to reinforce their evolutionary relationship within the $\mathrm{Nr} 2 \mathrm{f}$ family. The invertebrate $\mathrm{Nr} 2 \mathrm{f} 1 / 2 / 5 / 6$ group is more closely related to the branch that includes $\mathrm{Nr} 2 \mathrm{f} 1 / 2 \mathrm{~s}$ from the agnathan (lamprey and hagfish) and vertebrate $\mathrm{Nr} 2 \mathrm{f} 1$ and $\mathrm{Nr} 2 \mathrm{f} 2$ proteins than the vertebrate $\mathrm{Nr} 2 \mathrm{f} 5$ and $\mathrm{Nr} 2 \mathrm{f} 6$ subfamilies (Fig 2). The clustering of the invertebrate Nr2f1/2/5/6 and agnathan Nr2f1/2 proteins with $\mathrm{Nr} 2 \mathrm{f} 1$ and $\mathrm{Nr} 2 \mathrm{f} 2$ of gnathostomes suggests that these paralogous gnathostome genes arose from distinct duplicative events during vertebrate evolution [41, 42]. In addition, the three agnathan Nr2f proteins found in Sea lamprey (Petromyzon marinus) and hagfish (Eptatretus burgeri) (Fig 2), which we have called Nr2f1/2A, Nr2f1/2B, and $\mathrm{Nr} 2 \mathrm{f} 1 / 2 \mathrm{C}$, diverge and cluster together at the base of the vertebrate $\mathrm{Nr} 2 \mathrm{f1}$ and $\mathrm{Nr} 2 \mathrm{f} 2$ proteins (Fig 2), supporting that the duplications leading to these proteins in agnathans were distinct from those that gave rise to the Nr2f paralogs in gnathostomes.

Our analysis also shows that $\mathrm{Nr} 2 \mathrm{f} 5$ and Nr2f6 form a separate branch and are sisters groups, implying that they are paralogous and derived from the second of the vertebrate WGDs [41, 42]. Importantly, while all gnathostomes examined have retained $\mathrm{Nr} 2 \mathrm{f} 1, \mathrm{Nr} 2 \mathrm{f} 2$ and $\mathrm{Nr} 2 \mathrm{f} 6$, current genomic data support that $\mathrm{Nr} 2 \mathrm{f} 5$ has been independently lost by multiple vertebrate groups. Cartilaginous fish, including Whale shark (Rinchodon typus) [46] and the Great white shark (Carcharadon charcarias) [47], have retained Nr2f5 genes, while they are absent in chimaera [48] and skates (S3 File). In amniotes, $N r 2 f 5$ genes were found in reptiles, such as American alligator (Alligator mississippiensis), gecko (Gekko japonicus), and the Green sea turtle (Chelonia mydas) (Fig 2; S1 Fig), but absent from the Chinese sea turtle (Pelodiscus sinesis), as well as birds and mammals (S3 File). Although previous work had also designated a Xenopus laevis Nr2f4 [19], our data indicate there is no evidence for a separate Nr2f4 subfamily and that this gene should be called Nr2f5. Comparing the vertebrate $\mathrm{Nr} 2 \mathrm{f} 1 / \mathrm{Nr} 2 \mathrm{f} 2$ and $\mathrm{Nr} 2 \mathrm{f} 5 / \mathrm{Nr} 2 \mathrm{f} 6$ clusters, the branching and distances from our phylogenetic trees indicate that $\mathrm{Nr} 2 \mathrm{f} 1$ and $\mathrm{Nr} 2 \mathrm{f} 2$ are more highly conserved, while Nr2f6 TFs comprise the most divergent vertebrate Nr2f subfamily (Fig 2; S1 Fig).

To analyze the impact of additional WGDs on $N r 2 f$ genes, which took place in teleosts [17, 18], and specifically, in salmonids [49], we surveyed the Nr2f proteins of 12 teleost species (Fig 2; S1 Fig). Consistent with the WGDs in these species, there was a tremendous expansion of the $N r 2 f$ family in this clade, although it was accompanied by differential $N r 2 f$ paralog losses in some species (Fig 2; S1 Fig). To further interrogate the evolution of the Nr2f proteins, we examined alignments of the highly conserved zinc-fingers (Znf) within their DNA-binding domains (DBDs) using representatives from each subfamily (Fig 3). Although there is a high degree of conservation in all the examined $\mathrm{Nr} 2 \mathrm{fs}$, the amino acid changes in the DBDs parallels 


\section{Znf I Znf II}

T. adhaerens

N. vectensis

A. millepora

A. millepora

N. vectensis

A. millepora

$N$. vectensis

A. millepora

D. melanogaster

C. elegans

L. gigantea

Nr2f

$\operatorname{Nr} 2 \mathrm{f} 1 / 2 / 5 / 6 a$

$\mathrm{Nr} 2 \mathrm{f} 1 / 2 / 5 / 6 \mathrm{a}$

$\mathrm{Nr} 2 \mathrm{f} 1 / 2 / 5 / 6 \mathrm{~b}$

$\mathrm{Nr} 2 \mathrm{f} 1 / 2 / 5 / 6 \mathrm{~b}$

$\mathrm{Nr} 2 \mathrm{f} 1 / 2 / 5 / 6 \mathrm{c}$

$\mathrm{Nr} 2 \mathrm{f} 1 / 2 / 5 / 6 \mathrm{c}$

$\mathrm{Nr} 2 \mathrm{f} 1 / 2 / 5 / 6 \mathrm{~d}$

$\mathrm{Nr} 2 \mathrm{f} 1 / 2 / 5 / 6 \mathrm{~d}$

$\mathrm{Nr} 2 \mathrm{f} 1 / 2 / 5 / 6$

$\mathrm{Nr} 2 \mathrm{f} 1 / 2 / 5 / 6$

$\mathrm{Nr} 2 \mathrm{f} 1 / 2 / 5 / 6$

s. kowalevskii $\mathrm{Nr} 2 \mathrm{f} 1 / 2 / 5 / 6$

s. purpuratus $\mathrm{Nr} 2 \mathrm{f} 1 / 2 / 5 / 6$

C. robusta

o. dioica

$\mathrm{Nr} 2 \mathrm{f} 1 / 2 / 5 / 6$

$\mathrm{Nr} 2 \mathrm{f} 1 / 2 / 5 / 6$

B. belcheri

$\mathrm{Nr} 2 \mathrm{f} 1 / 2 / 5 / 6$

$P$. marinus

P. marinus

E. burgeri

$\operatorname{Nr} 2 \mathrm{f} 1 / 2 \mathrm{~A}$

$\mathrm{Nr} 2 \mathrm{f} 1 / 2 \mathrm{~B}$

$\mathrm{Nr} 2 \mathrm{f} 1 / 2 \mathrm{C}$

$\mathrm{Nr} 2 \mathrm{f} 1 / 2 \mathrm{~A}$

$\mathrm{Nr} 2 \mathrm{f} 1 / 2 \mathrm{~B}$

$E$. burgeri

$\mathrm{Nr} 2 \mathrm{f} 1 / 2 \mathrm{C}$

C. milii

Nr2f1

carcharias Nr2f1

L. oculatus Nr2f1

D. rerio Nr2f1a

D. rerio $\mathrm{Nr} 2 \mathrm{f} 1 \mathrm{~b}$

L. Chalumnae Nr2f1

$X$. tropicalis $\mathrm{Nr} 2 \mathrm{f} 1$

F. albicollis Nr2f1

G. japonicus Nr2f1

C. mydas Nr2f1

H. sapiens NR2F1

C. milii Nr2f2

C. carcharias Nr2f2

L. oculatus Nr2f2

D. rerio $\mathrm{Nr} 2 \mathrm{f} 2$

L. Chalumnae Nr2f2

$x$. tropicalis Nr2f2

$F$. albicollis Nr2f2

G. japonicus Nr2f2

C. mydas Nr2f2

H. sapiens NR2F2

C. carcharias Nr2f5

L. oculatus Nr2f5

D. rerio Nr2f5

L. chalumnae Nr2f5

$\mathrm{x}$. tropicalis Nr2f5

C. mydas Nr2f5

C. milii Nr2f6

C. carcharias Nr2f6

L. oculatus Nr2f6

D. rerio Nr2f6a

D. rerio $\mathrm{Nr} 2 \mathrm{f} 6 \mathrm{~b}$

L. chalumnae Nr2f6

$X$. tropicalis Nr2f6

$F$. albicollis Nr2f6

G. japonicus Nr2f6

C. mydas Nr2f6

H. sapiens NR2F6
CLICGDRSNGRHYG ISCEGC CTCSANCKITKANRNOCOFC CAVCGDKSSGKHYG FTCEGC CRASRDCPIDQHHRNQCQYC CAVCGDKSSGKHYG FTCEGC CRASRNCPIDQHHRNQCQYC CAVCGDKSTGKHYG STCEGC CREQNTCAIDRNSRSRCPSC CVVCGDKSSGKHYG FTCEGC CRGONTCAIDRNSRSRCPSC CAVCGDKSSGKHYG YTCEGC CRGFKNCPVDIQHRNHCQYC CAVCGDKSTGKHYG STCEGC CRGFKNCPVDIQHRNHCQYC CAVCSAPSSGRHYG FTCEGC CEGSGSCRVDKQNRTQCQAC CSVCGDHSTGRHYGANTCEGC CRVTGCCPVNKRYRNSCQYC

CVVCGDKSSGKHYGQFTCEGC CRGSRNCPIDQHHRNQCQYC CVVCGDKSSGKHYGQFSCEGC CRATKNCAIDVQHRNQCQYC CVVCGDKSSGKHYGQYTCEGC CRGNKNCPIDOHHRNQCOYC CVVCGDKSSGKHYGQFTCEGC CRANRNCPIDQHHRNQCQYC CVVCHDKSSGKHYGQFTCEGC CRANRNCPIDQHHRNQCQYC CVVCGDKSSGKHYGQYTCEGC CRGNRNCPIDQHHRNQCQYC CVVCGDKSSGKHYGQFTCEGC CRGNRSCPIDOHHRNQCOYC CVVCGDKSSGKHYGQFTCEGC CRGNRTCPIDQHHRNQCQYC

CVVCGDKSSGKHYGQFTCEGC CRANRNCPIDQHHRNQCOYC CVVCGDKSSGKHYGOFTCEGC CRANRNCPIDOHHRNOCOYC CVVCGDKSSGKHYGQLTCEGC CRAARACPIDQHHRNQCQYC CVVCGDKSSGKHYGQFTCEGC CRANRNCPIDQHHRNQCQYC CVVCGDKSSGKHYGQFTCEGC CRANRNCPIDQHHRNOCOYC CVVCGDKSSGKHYGQFTCEGC CRAARNCPIDQHHRNQCQYC

CVVCGDKSSGKHYGQFTCEGC CRANRNCPIDQHHRNQCQYC CVVCGDKSSGKHYGOFTCEGC CRANRNCPIDOHHRNOCOYC CVVCGDKSSGKHYGOFTCEGC CRANRNCPIDOHHRNOCOYC CVVCGDKSSGKHYGQFTCEGC CRANRNCPIDQHHRNQCQYC CVVCGDKSSGKHYGQFTCEGC CRANRNCPVDQHHRNQCQYC CVVCGDKSSGKHYGQFTCEGC CRANRNCPIDQHHRNQCQYC CVVCGDKSSGKHYGOFTCEGC CRANRNCPIDOHHRNOCOYC CVVCGDKSSGKHYGQFTCEGC CRANRNCPIDQHHRNQCQYC CVVCGDKSSGKHYGQFTCEGC CRANRNCPIDQHHRNQCQYC CVVCGDKSSGKHYGQFTCEGC CRANRNCPIDQHHRNQCQYC CVVCGDKSSGKHYGQFTCEGC CRANRNCPIDQHHRNQCQYC

CVVCGDKSSGKHYGQFTCEGC CRANRNCPIDQHHRNQCQYC CVVCGDKSSGKHYGOFTCEGC CRANRNCPIDOHHRNOCOYC CVVCGDKSSGKHYGOFTCEGC CRANRNCPIDQHHRNQCOYC CVVCGDKSSGKHYGQFTCEGC CRANRNCPIDQHHRNQCQYC CVVCGDKSSGKHYGQFTCEGC CRANRNCPIDQHHRNQCQYC CVVCGDKSSGKHYGQFTCEGC CRANRNCPIDQHHRNQCOYC CVVCGDKSSGKHYGQFTCEGC CRANRNCPIDQHHRNQCQYC CVVCGDKSSGKHYGQFTCEGC CRANRNCPIDQHHRNQCQYC CVVCGDKSSGKHYGQFTCEGC CRANRNCPIDQHHRNQCQYC CVVCGDKSSGKHYGQFTCEGC CRANRNCPIDQHHRNQCQYC

CMVCGDKSSGKHYGQFTCEGC CRGSRNCPIDQHHRNECQHC CMVCGDKSSGKHYGQFTCEGC CRGNRDCPIDQHHRNQCQYC CMVCGDKSSGKHYGQFTCEGC CRGNRDCPIDQHHRNQCQYC CMVCGDKSSGKHYGQFTCEGC CRGNRDCPIDQHHRNQCQYC CLVCGDKSSGKHYGQFTCEGC CRGNRDCPIDQHHRNQCQYC CMVCGDKSSGKHYGQFTCEGC CRSNRECPIDQHHRNQCQHC

CVVCGDRASGKHYGQFTCEGC CRSNRDCHIDQHHRNQCQYC CVVCGDRASGKHYGOFTCEGC CRSNRDCQIDQHHRNQCQYC CVVGGDKSSGKHYG FTCEGC CRSNRDCQIDQHHRNQCQYC CVVCGDKSSGKHYG FTCEGC CRSNRDCQIDQHHRNQCQYC CVVCGDKSSGKHYG FTCEGC CRSNRECQIDQHHRNQCQYC CVVCGDKSSGKHYGAFTCEGC CRSNRDCQIDQHHRNQCQYC CVVCGDKSSGKHYGQFTCEGC CRANRNCPIDQHHRNQCQYC CVVCGDKSSGKHYG FTCEGC CRSNRDCQIDQHHRNOCOYC CVVCGDKSSGKHYG FTCEGC CRSNRDCQIDQHHRNQCQYC CTVCGDKSSGKHYG FTCEGC CRSNRDCQIDQHHRNQCQYC CVVCGDKSSGKHYG FTCEGC CRSNRDCQIDQHHRNQCQYC

Fig 3. Zinc finger (Znf) motifs within the DBD of the Nr2f family. Alignments of first (I) and second (II) Znfs found in Nr2f TFs. Yellow represents highly conserved amino acids throughout all species. White indicates amino acids that are not conserved. Turquoise and blue indicate amino acid changes that are conserved within Znf I of Nr2f5 and -6, respectively. The valine change found in some Nr2f6 LBDs is also found in the placozoan and cnidaria Nr2fs. Magenta and red indicate amino acid changes at the same residue that are conserved within Znf II of Nr2f5 and Nr2f6, respectively. A glycine residue is also found at the same position in some cnidaria and invertebrate $\mathrm{Nr} 2 \mathrm{fs}$. Green indicates a conserved change found in most $\mathrm{Nr} 2 \mathrm{f} 5$ and Nr2f6 Znf IIs.

https://doi.org/10.1371/journal.pone.0254282.g003 
the phylogenetic results of the whole proteins. The $\mathrm{Nr} 2 \mathrm{f1} / 2 / 5 / 6$ proteins of early-branching eumetazoans showed a high degree of variability and multiple differences with respect to $\mathrm{Nr} 2 \mathrm{f1} / 2 / 5 / 6$ DBDs of protostome and deuterostome invertebrates and the Nr2f DBDs in vertebrates. There is high similarity between $\mathrm{Nr} 2 \mathrm{f} 1 / 2, \mathrm{Nr} 2 \mathrm{f} 1$ and $\mathrm{Nr} 2 \mathrm{f} 2 \mathrm{DBDs}$ in agnathans and gnathostomes, whereas Nr2f5 and Nr2f6 DBDs of gnathostomes exhibited specific changes that are consistent with their positions in the phylogenetic trees (Figs 2 and 3). Interestingly, single amino acid changes found in most $\mathrm{Nr} 2 \mathrm{f} 5$ and $\mathrm{Nr} 2 \mathrm{f} 6$ proteins are also found in some early-branching eumetazoans and invertebrate $\mathrm{Nr} 2 \mathrm{fs}$. However, the functional significance of these changes, if any, is not clear. Thus, our phylogenetic reconstruction of $\mathrm{Nr} 2 \mathrm{f}$ genes in metazoans overall shows the presence of single orthologs in invertebrates and a significant expansion of the family in vertebrates that is punctuated with independent losses of Nr2f5 in some cartilaginous fishes and amniotes.

\section{$N r 2 f$ genes have conserved intron codes}

To complement the phylogenetic analysis of $N r 2 f$ genes, we first analyzed the conservation of $N r 2 f$ intron/exon structure [50-52]. Intron/exon junctions from early-branching eumetazoans and vertebrates matching the transcripts and the translated proteins were mapped and given a score for the intron phases (S4 File), with 0, 1 and 2 introns falling before the first, second and third bases of a codon, respectively. The introns were then mapped on a protein alignment comprising the highly conserved Nr2f protein DBDs and LBDs (S4 File). We found that two "phase 1" introns (one within the 3' end of the DBD and one within the LBD) are preserved in all the extant Nr2f subfamilies (Fig 4A; S4 File). However, Nr2f6 genes also have a "phase 2" intron inside the second zinc-finger domain belonging to the DBD (Fig 4A; S4 File). The conservation of intron/exon junctions in the examined $N r 2 f$ genes allows two groups to be distinguished: one constituted by $N r 2 f, N r 2 f 1 / 2 / 5 / 6, N r 2 f 1 / 2, N r 2 f 1, N r 2 f 2, N r 2 f 5$, and one comprising only vertebrate $\mathrm{Nr} 2 \mathrm{f6}$ (Fig $4 \mathrm{~B}$ ), implying this unique intron/exon boundary originated after the duplication event that generated Nr2f5 and Nr2f6. Thus, our analysis of intron/ exon boundaries demonstrates the existence of a highly conserved intron code throughout eumetazoan $\mathrm{Nr} 2 f$ family members and the divergence of $\mathrm{Nr} 2 \mathrm{f} 6$ genes following the second WGD.

\section{Synteny analysis defines differential duplications and losses in the $\mathrm{Nr} 2 f$ family}

In order to confirm the specific homologies indicated from the phylogenetic analysis, we next carried out an examination of synteny within the $\mathrm{Nr} 2 \mathrm{f}$ genomic environments. With respect to representatives of the more ancient $N r 2 f$ genes, we did not find evidence of synteny between the single $N r 2 f$ in the placozoan T. adhaerens and the multiple $N r 2 f s$ in cnidarians. However, the location of the four Nr2f genes in N. vectensis and A. millepora genomes indicates they were likely derived from an initial duplication event followed by a tandem duplication event (Fig 5). Interestingly, Mef2 and $R b m 8$ homologs were associated with $N r 2 f 1 / 2 / 5 / 6 b$ in N. vectensis and A. millepora, while an Arrdc homolog is associated with $N r 2 f 1 / 2 / 5 / 6 a$ in N. vectensis. In vertebrates, $M e f 2$ paralogs (Mef2c, Mef2b, Mef2b) are associated with $N r 2 f 1, N r 2 f 2$, and $N r 2 f 6, A r r d c$ paralogs (Arrdc3, Arrdc4, Txnip/Arrdc6) are associated with Nr2f1, Nr2f2, and $\mathrm{Nr} 2 \mathrm{f5}$, and Rbm8a is associated with Nr2f5 (Figs 6-8), implying an ancient association of these genes within eumetazoan genomes.

In invertebrates, despite the synteny suggested between $\mathrm{Nr} 2 f, \mathrm{Mef} 2$, Arrdc, and $\mathrm{Rbm} 8$ genes in cnidaria and vertebrates, we only found limited preservation of the $N r 2 f 1 / 2 / 5 / 6$ loci between two slow-evolving deuterostomes: the amphioxus (B. belcheri) [53] and the hemichordate 

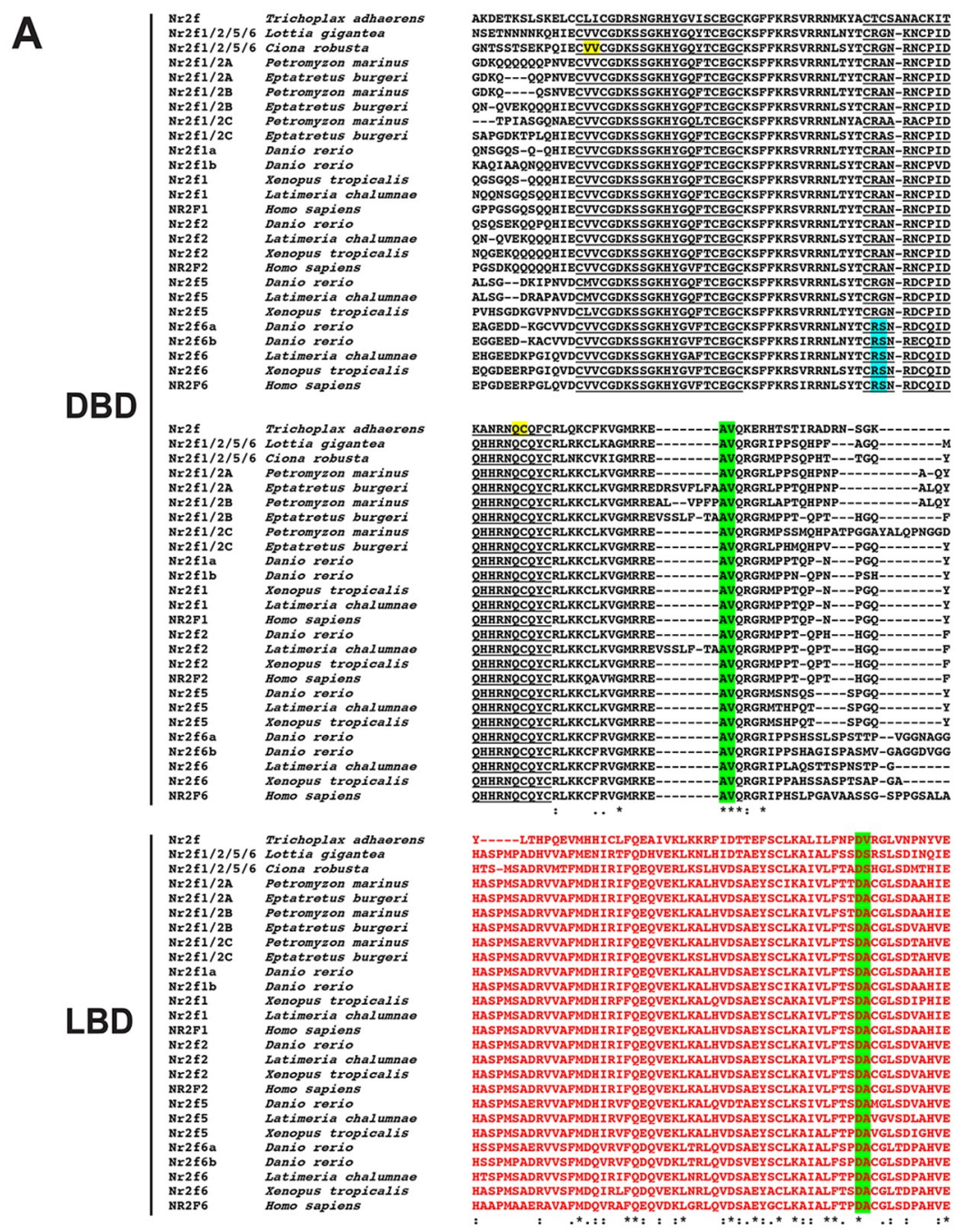

B Sonopus tropicalis
Bomo sapiens

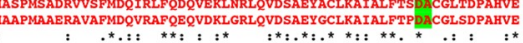

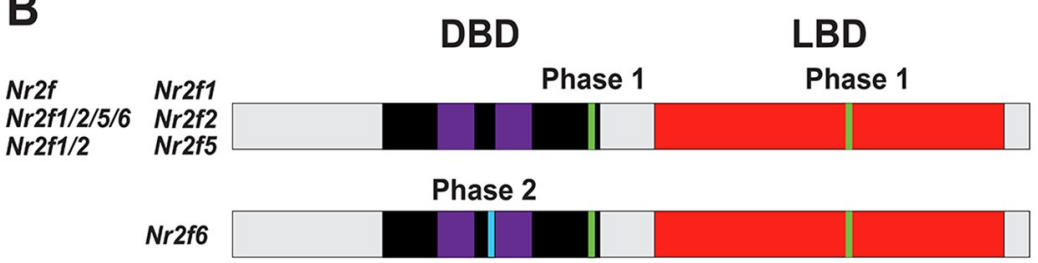

Fig 4. Intron code of the $N r 2 f$ family in metazoans. (A) Protein alignment showing conservation of intron/exon structures within the DBDs (black) and LBDs (red) of Nr2f members. Znfs in the DBDs are underlined. Phase 0 introns-yellow, phase 1 introns-green, and phase 2 introns-turquoise. Asterisks indicate $100 \%$ amino acid conservation. Colons indicate high levels ( $>90 \%)$ amino acid conservation. Periods indicate moderate levels $(50-89 \%)$ of amino acid conservation. (B) Schematization of intron/exon boundaries of $N r 2 f$ genes as they relate the Nr2f protein DBD and LBDs. Black box indicates DBD. Purple boxes represent the zinc-fingers motifs within the DBD. Red boxes indicate the LDB. Colored bars indicate the conserved Nr2f Phase 1 introns (green) and the Nr2f6-specific Phase 2 intron (turquoise).

https://doi.org/10.1371/journal.pone.0254282.g004

(S. kowalevskii) [54] (S2 Fig). However, the limited synteny still corroborates the existence of the invertebrate Nr2f1/2/5/6 cluster shown in the phylogenetic trees (Fig 2; S1 Fig). Furthermore, the only remaining synteny between $\mathrm{Nr} 2 f 1 / 2 / 5 / 6$ in invertebrates and vertebrate orthologs appears to be the linkage between UNC45A and NR2F2 of primates and Unc45a and 


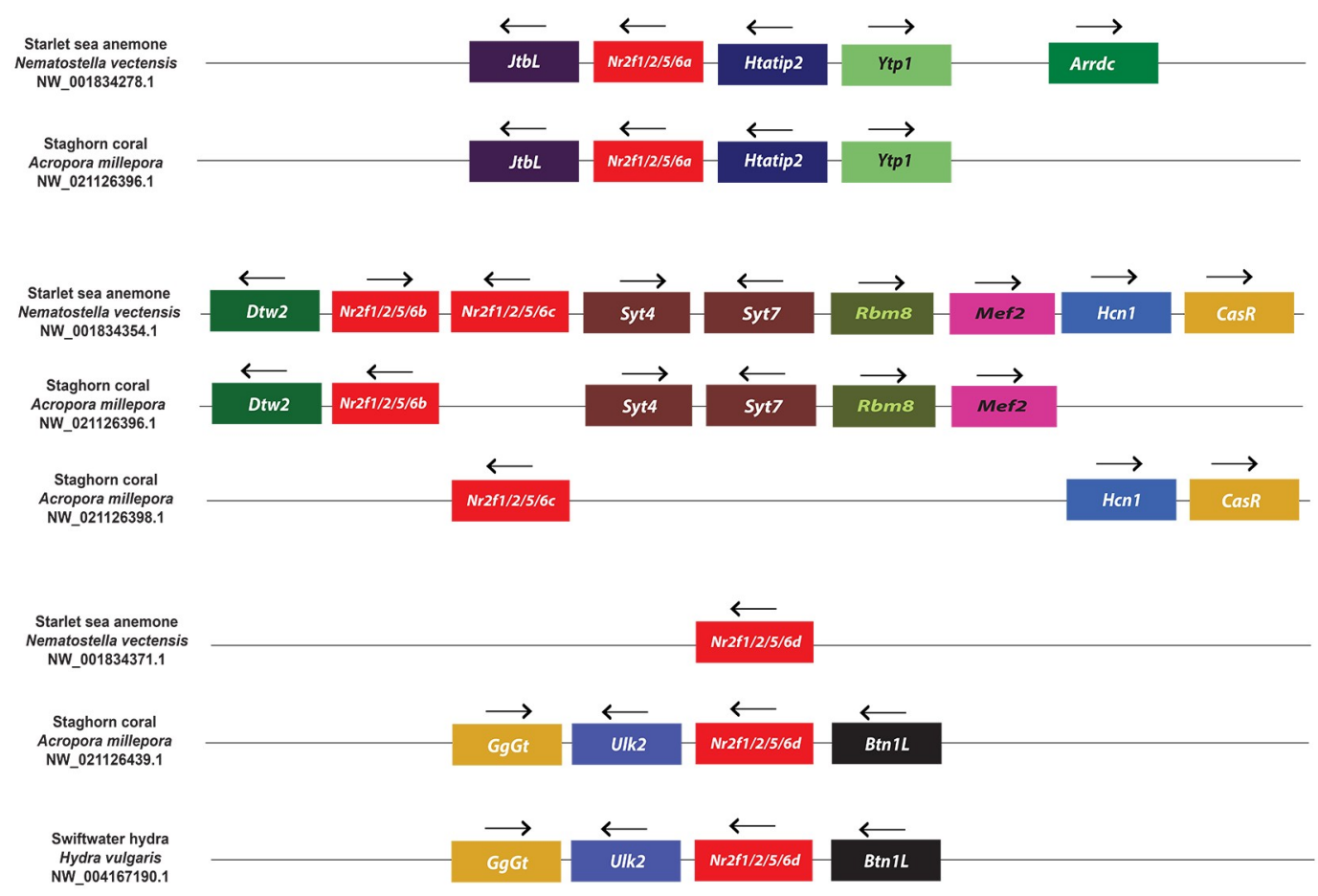

Fig 5. Synteny analysis of $N r 2 f 1 / 2 / 5 / 6$ genes in cnidaria. Schematic of the loci flanking $N r 2 f 1 / 2 / 5 / 6$ gene duplications in cnidaria $N$. vectensis, A. millepora, and H vulgaris. Only the one $H$. vulgaris gene presently has available genomic information. Arrows indicate transcription orientation.

https://doi.org/10.1371/journal.pone.0254282.g005

Nr2f1/2/5/6 of the tunicate C. robusta (S3 Fig), which is considered the closest living relative of vertebrates [55]. Focusing on Nr2f1 and Nr2f2 in the genomes of gnathostomes, including Great white sharks, coelacanths, spotted gars, zebrafish, chickens, and humans, we found a high degree of synteny for $N r 2 f 1$ and Nr2f2 loci and conservation of the location of flanking genes among these taxa (Fig 6). Specifically, $N r 2 f 1$ and $N r 2 f 2$ genes exhibited remarkably conserved syntenic environments, clustering with putative orthologs belonging to other families. Lysmd3, Arrdc3, Mctp1 and Mef2a flank Nr2f1 orthologs, while Nr2f2 orthologs are flanked by Lysmd4, Arrdc4, Mctp2 and Mef2c paralogs. Furthermore, in teleosts like zebrafish, two Nr2f1 Ohnologs (nr2f1a and $n r 2 f 1 b$ ) also shared significant conservation of paralogous genes (Fig 6), which is consistent with an origin from the teleost-specific genome duplication (TSGD) [17, 18]. However, the $n r 2 f 1 b$ gene has been lost by several teleost species (Fig 2; S1 Fig). Although the genomic information is somewhat fragmented, orthologs of flanking genes found in gnathostome Nr2f1 and Nr2f2, such as Arrdc2/3, Lysmd3, Fam172a, were also found near each of the three Sea lamprey Nr2f1/2 genes and the hagfish Nr2f1/2C gene (S4 Fig), which is consistent with these genes arising from genome duplication(s) within the agnathan lineage [56]. Together, these results suggest that $N r 2 f 1$ and $N r 2 f 2$ of gnathostomes have a common origin and are derived from a WGD event [41, 42].

Examining Nr2f5 loci in representative gnathostomes showed a high degree of conservation in both species that have retained and lost the gene. The adjacent genomic environments in the majority of examined $N r 2 f 5$ loci have retained an association with $R b m 8 a$ (Fig 7), whose homolog in cnidarians flanks $N r 2 f 1 / 2 / 5 / 6 b$ (Fig 5). The synteny is generally not shared with gnathostome $N r 2 f 1$ and $N r 2 f 2$ orthologs (Fig 6). However, the $N r 2 f 5$ loci in coelacanth and amphibians have retained Txnip (Fig 7), which is also named Arrdc6. As aforementioned, 

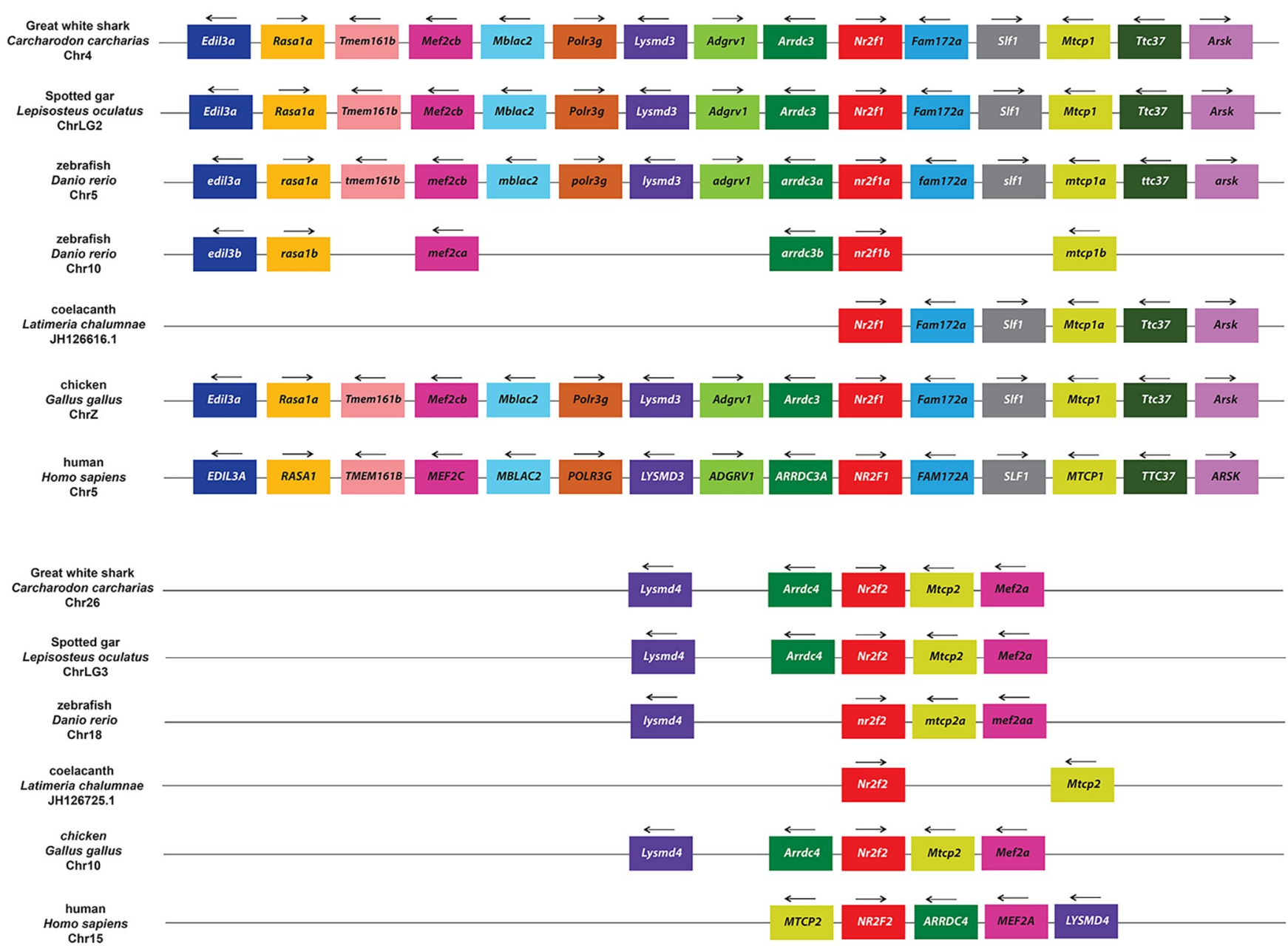

Fig 6. Synteny analysis of vertebrate $N r 2 f 1$ and $N r 2 f 2$ genes. Schematization of conserved genomic environments of gnathostome $N r 2 f 1$ and $N r 2 f 2$ genes (red rectangles) in selected species with relative chromosomes/scaffolds. Flanking orthologous genes are represented employing rectangles of the same color. Arrows indicate transcription orientation.

https://doi.org/10.1371/journal.pone.0254282.g006

Arrdc family members flank the N. vectensis Nr2f1/2/5/6a (Fig 5) and both Nr2f1 and Nr2f2 genes (Fig 6). Interestingly, amniotes that have lost Nr2f5 (representatives including Chinese soft-shell turtles, chickens, and humans) (Fig 7; S3 File) have largely preserved the flanking genomic loci that are present in cartilaginous fish, zebrafish, coelacanth, frogs, and Green see turtles (Fig 7). In contrast, the absence of Nr2f5 in some cartilaginous fish, such as C. milii, correlates with the lack of the entire locus. Within the Actinopterygii (ray-finned fishes), the synteny of genes has been lost only on one side of the Nr2f5 loci (Fig 7). With respect to the lamprey, its $\mathrm{Nr} 2 \mathrm{fl} / 2 \mathrm{C}$ ortholog is flanked by a Bola1 ortholog, as well as orthologs of genes that flank gnathostome $N r 2 f 1$ and Nr2f2 (S4 Fig; Figs 6 and 7), which further suggests ancestral linkage with the single Nr2f1/2/5/6 genes (Fig 2; S1 Fig).

As might be expected given the divergence, the Nr2f6 subfamily did not share many common elements with the other Nr2floci in gnathostomes (Fig 8). However, Mef2b was syntenic in Great white sharks, Spotted gar, chicken, and human genomes, similar to cnidarian Nr2fl/ $2 / 5 / 6 b$ (Fig 5) and gnathostome Nr2f1 and Nr2f2 (Fig 6). Within gnathostomes, the Nr2f6 loci were highly conserved from cartilaginous fish to mammals, although there were significant gene losses surrounding $n r 2 f 6 a$ and $n r 2 f 6 b$ loci in zebrafish and one side of the Nr2f6 locus in 


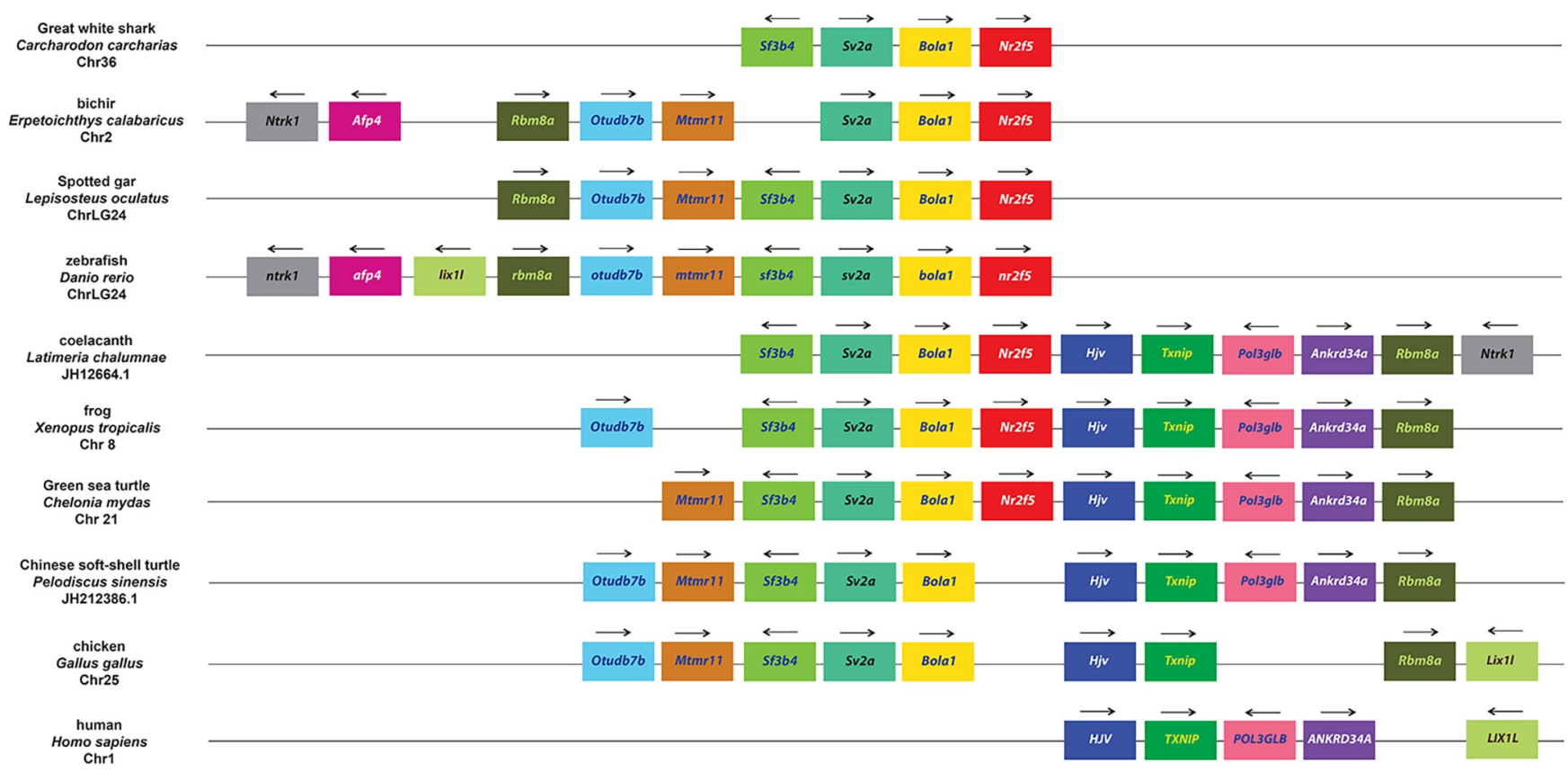

Fig 7. Synteny analysis of vertebrate Nr2f5 genes. Schematization of conserved genomic environments of gnathostome Nr2f5 genes (red rectangles) in selected species with relative chromosomes/scaffolds. Flanking orthologous genes are represented using rectangles of the same color. Arrows indicate transcription orientation.

https://doi.org/10.1371/journal.pone.0254282.g007

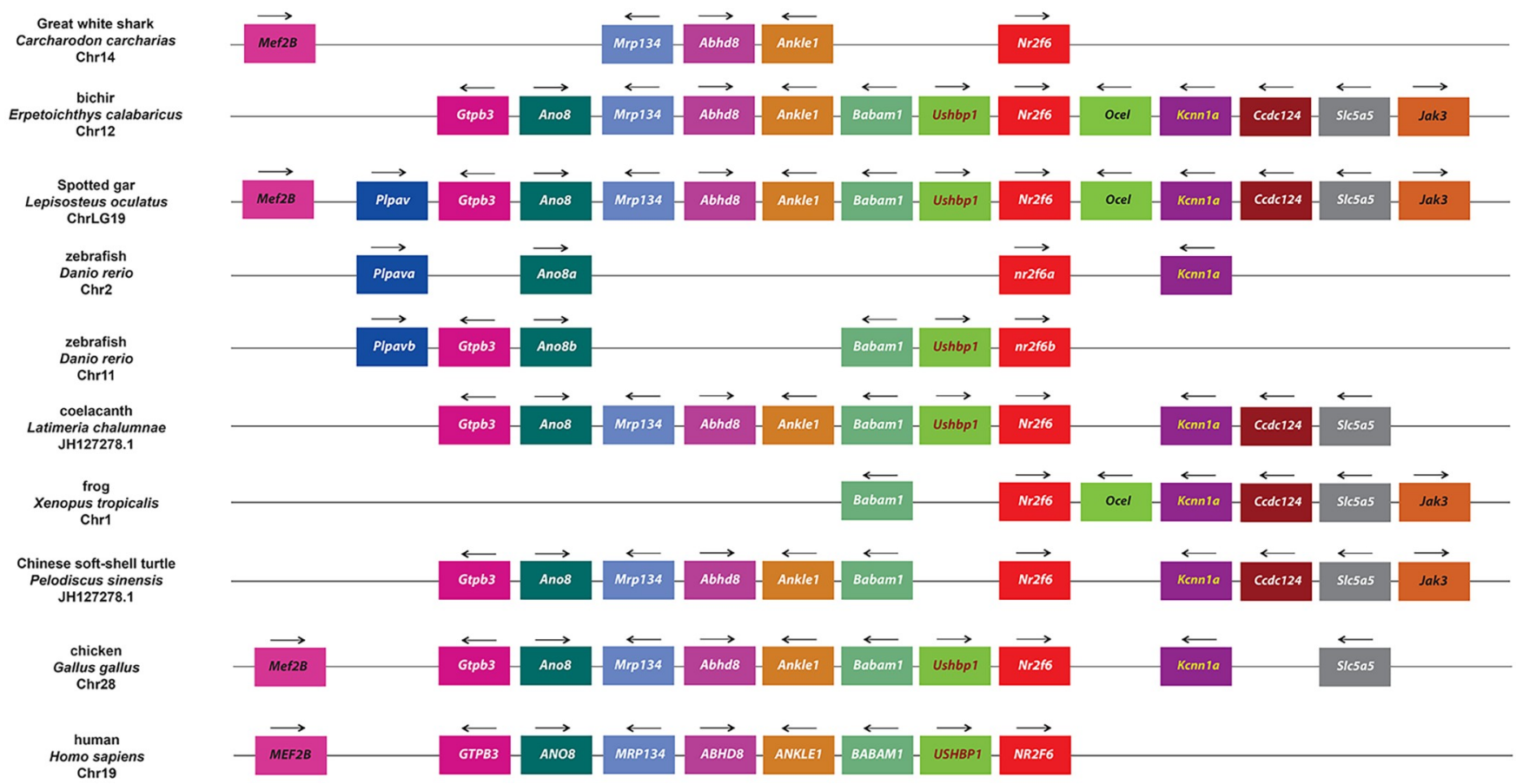

Fig 8. Synteny analysis of vertebrate $\mathbf{N r} 2 \mathrm{f6}$ genes. Schematization of conserved genomic environments of gnathostome $\mathrm{Nr} 2 f 6$ genes (red rectangles) in selected species with relative chromosomes/scaffolds. Flanking orthologous genes are represented using the same color code. Arrows indicate transcription orientation.

https://doi.org/10.1371/journal.pone.0254282.g008 
humans. Furthermore, the presence of conserved orthologs (ano8a and ano8b, plvapa and plvapb) flanking $n r 2 f 6 a$ and $n r 2 f 6 b$ zebrafish genes suggested that they originated from the TSGD. Together, these findings show that despite the greater divergence of the Nr2f5 and $\mathrm{Nr} 2 f 6$ within vertebrates the genomic environments have retained some synteny and surrounding $\mathrm{Nr} 2 f 5$ and $\mathrm{N} r 2 f 6$ loci are highly conserved within gnathostomes.

\section{Effects of TSGD on the $N r 2 f$ gene repertoire}

We next wanted to measure the impact of the series of additional WGDs that have occurred in teleosts on $N r 2 f$ gene number (Fig 2; S1 Fig). For this comparison, we examined all the Nr2f loci in zebrafish, the Asian arowana (S. formousus), which is documented to retain duplicates [57], and the Atlantic salmon (S. salar), which has a salmonid-specific genome duplication (SSGD) [49]. We found that each of these teleosts retained two Nr2f1 Ohnologs (Fig 9), suggesting they either were not duplicated or that one pair of Ohnologs was lost in salmonids. Zebrafish lost one $n r 2 f 2$ Ohnolog, maintaining only the $n r 2 f 2 a$ ortholog, while Asian arowana retained two Nr2f2 Ohnologs. Salmonids have $3 N r 2 f 2$ genes (Nr2f2a1, Nr2f2a2, and Nr2f2b1), due to a loss of the one of the Nr2f2b Ohnologs following their additional WGD. With respect to Nr2f5, only Atlantic salmon showed two copies, implying these were generated during the SSGD event, as suggested by the presence of two Nr2f5 Ohnologs in other salmonids (Oncorhynchus spp., Coregonus clupeaformis) (S5 File). Finally, zebrafish and Asian arowana each possess two Nr2f6 genes, while Atlantic salmon has 3 similar to what is found in the Nr2f2 subfamily (Fig 9). Inspecting other teleost Nr2f gene family repertoires (Fig 2; S1 Fig), we
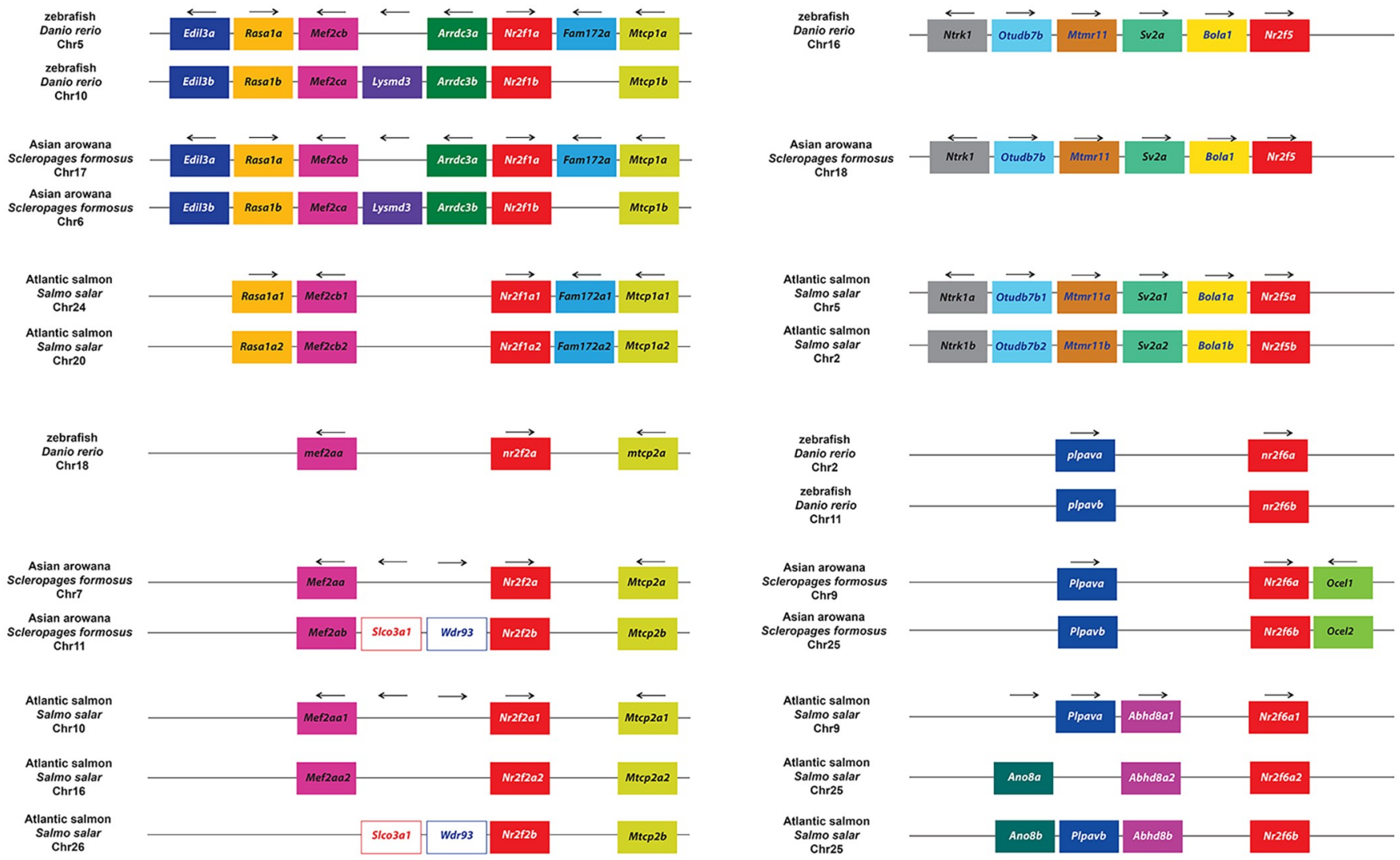

Fig 9. Synteny analysis of $\mathbf{N r} 2 f$ genes in teleosts. Comparison of $N r 2 f$ genome environments in selected teleosts (zebrafish, Asian arowana, Atlantic salmon) with relative chromosomes/scaffolds. Rectangles of the same color represent flanking orthologous genes. Arrows indicate transcription orientation.

https://doi.org/10.1371/journal.pone.0254282.g009 
found that the Channel catfish (Ictalurus punctatus), Red-bellied piranha (Pygocentrus nattereri), cavefish (Astyanax mexicanus) and Sheepshead minnow (Cyprinodon variegatus) all retained only Nr2f6b. The Sheepshead minnow and Princess cichlid (Neolamprologus brichardi) also lost Nr2f5. However, other cichlids like Nile tilapia (Oreochromis niloticus) and Zebra mbuna (Maylandia zebra) did not lose Nr2f5 (S5 File). Intriguingly, the Monterrey platifish (Xiphophorus couchianus) is the only gnathostome without any Nr2f1 paralogs, differing from its sibling species, the common platifish (X. maculatus), which possesses Nr2f1a. Therefore, teleosts show an expansion of Nr2f genes following TSGD and SSGD, which were followed by high variability in species-specific losses of $\mathrm{Nr} 2 f$ Ohnologs.

\section{Discussion}

We have performed an examination of $N r 2 f$ gene evolution in metazoans. Our analysis corroborates previous work showing that $\mathrm{Nr} 2 \mathrm{f}$ genes are present in some representative early-branching eumetazoans (placozoans and cnidarians) [15,58], but that they are absent in earlybranching metazoans, i.e. sponges and ctenophores $[15,58]$. Importantly, our data support a model in which a single $N r 2 f$ gene, which is present in a representative placozoan, predated a $N r 2 f 1 / 2 / 5 / 6$ subfamily found in cnidaria and six Bilateria subfamilies that include $N r 2 f 1 / 2 / 5 / 6$ (found in invertebrate protostome and deuterostomes), $N r 2 f 1 / 2$ (found in agnathans), and $N r 2 f 1, N r 2 f 2, N r 2 f 5$, and Nr2f6 (found in vertebrates; Fig 10). Single, conserved Nr2f1/2/5/6 genes are predominantly found throughout invertebrate protostomes and deuterostomes and have even been retained in species traditionally considered gene losers, such as the tunicates $[52,59,60]$. There has been significant expansion and retention of Nr2fs in gnathostomes, particularly in teleosts. Although initial analysis in lampreys suggested they may possess only one $N r 2 f$ gene [61], our evolutionary assessment shows that extant agnathans have three $N r 2 f$ members, which appear to have originated in part from an agnathan WGD event [56]. Interestingly, the single $\mathrm{Nr} 2 \mathrm{f} 1 / 2 / 5 / 6$ proteins in invertebrates are also highly conserved at the

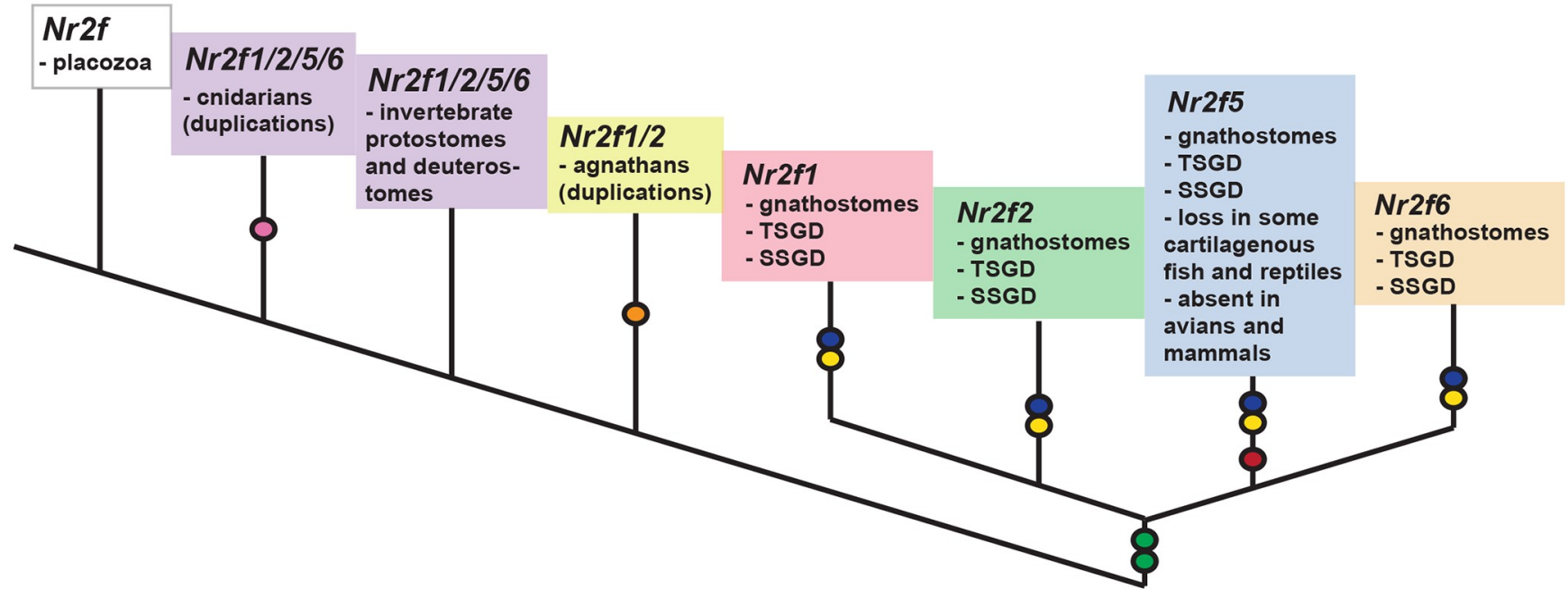

Fig 10. Model summarizing the evolutionary events of the $N r 2 f$ family in Metazoa. A single $N r 2 f$ of placozoans (white box) represents the ancestor of extant $N r 2 f s$. There were duplicative events specific to cnidaria leading to the expansion of $N r 2 f 1 / 2 / 5 / 6$ (pink circle). Invertebrate protostomes and deuterostomes have predominantly retained a single $\mathrm{Nr} 2 \mathrm{fl} / 2 / 5 / 6$ homolog. There were duplicative events specific to agnathans leading to an expansion of $N r 2 f 1 / 2$ genes (orange circle). WGDs within vertebrates (green circles) generated the four $N r 2 f s$ found in vertebrates, with $N r 2 f 1 / N r 2 f 2$ being paralogous and $N r 2 f 5 / N r 2 f 6$ being paralogous. Nr2f5 has been independently lost in multiple vertebrate groups (red circle). It is lost in some cartilaginous fish and turtles (reptilian amniotes), and is absent in avian and mammalian amniotes. Teleosts have additional $N r 2 f$ Ohnologs due to TSGDs (blue circles) and SSGDs (yellow circles). 
sequence level and cluster with the $\mathrm{Nr} 2 \mathrm{f} 1 / 2$ proteins in agnathans and $\mathrm{Nr} 2 \mathrm{f} 1$ and $\mathrm{Nr} 2 \mathrm{f} 2$ proteins in gnathostomes. Furthermore, our data support a parsimonious view that $N r 2 f 1$ and $\mathrm{Nr} 2 f 2$ are paralogous and $\mathrm{Nr} 2 \mathrm{f} 5$ and $\mathrm{Nr} 2 \mathrm{f} 6$ are paralogous, consistent with each of the $\mathrm{Nr} 2 \mathrm{f1} / 2$ and $\mathrm{Nr} 2 \mathrm{f5} / 6$ branches being created from an initial WGD [41, 42]. Within gnathostomes, the genomic environments of each the Nr2f1, Nr2f2, Nr2f5, and Nr2f6 orthologs have retained significant synteny of their loci $[16,21,22]$. Remarkably, while limited synteny exists between the $N r 2 f 1 / 2$ and $N r 2 f 5 / 6$ branches and within the $N r 2 f 5 / 6$ branch, members of these families have retained association with $M e f 2$, Arrdc, and $R b m 8$ homologs within their genomic environments, which is also found in cnidaria. However, this genomic association was not found in other examined invertebrate genomes. Our analysis also shows the Nr2f5 subfamily is the smallest in vertebrates, having been independently lost in multiple gnathostomes (some cartilaginous fishes, amniotes-some reptiles, absent in birds and mammals) (Fig 10). In contrast to $N r 2 f 5$, the $N r 2 f 6$ subfamily has been retained by all the evaluated gnathostomes, despite being the most divergent at the sequence level, with respect to synteny, and intron/exon structure.

Although overall there has been relatively limited comparative analysis of $\mathrm{Nr} 2 \mathrm{f}$ gene expression beyond major model organisms, integrating our phylogenetic assessment with available expression and functional analyses of the $N r 2 f$ members in evolutionarily distant animals [12, 14] presently supports a hypothesis that $\mathrm{Nr} 2 \mathrm{f}$ expression originated in neural tissue and regulation of neuronal differentiation may be the most ancient $N r 2 f$ function. Foremost, the two $N r 2 f$ members (both $N r 2 f 1 / 2 / 5 / 6 c$ ) of the diploblastic cnidaria H. vulgaris and H. echinata thus far examined appear to be expressed in neurons and have requirements in neurogenesis [12, 14]. Clearly, the expression of the additional Nr2f cnidarian homologs that have been identified needs to be examined and if found to be expressed in endoderm would alter this hypothesis. Nevertheless, the function of Nr2f1/2/5/6 orthologs of protostome invertebrates nematodes and flies have been extensively studied in neural tissues and neural sensory cell differentiation $[8,62,63]$. In invertebrate deuterostomes, the single $N r 2 f 1 / 2 / 5 / 6$ orthologs are expressed in neural tissue of sea urchin (Strongylocentrotus purpuratus), amphioxus, and sea squirt embryos $[11,64-66]$. Recent functional analysis of the Mediterranean sea urchin (Paracentrotus lividus) $\mathrm{Nr} 2 \mathrm{f} 1 / 2 / 5 / 6$ shows that it is required for the development of neural and ectodermal derivatives [67]. A Nr2f1/2/5/6 ortholog from the agnathan River lamprey (Lampetra fluviatilis) is also expressed in the developing nervous system [61]. However, our identification of three Nr2f1/2 members in agnathans suggests that additional expression and potentially functional analysis should be performed in the Sea lamprey (P. marinus) and/or hagfish (E. burgeri) to understand the conservation of the different agnathan paralogs compared to Nr2fs in vertebrates. Both $N r 2 f 1$ and $N r 2 f 2$ orthologs share overlapping central nervous system (CNS) expression in mouse and zebrafish $[16,21,68]$. However, $n r 2 f 1 a$ and $n r 2 f 2$ are both expressed more extensively in neural tissue of zebrafish embryos, while $N r 2 f 1$ is predominantly expressed in neural tissues of mice [21, 22]. Nr2f5 is expressed in neural tissue and derivatives, including in the eyes of zebrafish and newts [68-70]. Nr2f6 genes have conserved expression within the central nervous system of mammals [16], as well as both zebrafish $n r 2 f 6$ Ohnologs. Thus, all Nr2fs examined are expressed in neural tissue, with experiments in cnidaria and invertebrates presently supporting their ancestral requirements may be in neural cell differentiation.

While we propose that $N r 2 f s$ may have originated with requirements in neural differentiation, they are also required for the development of mesodermal and endodermal-derived tissues through Bilateria. Thus, it is interesting to consider some of these requirements in light of our phylogenetic analysis. In addition to neural differentiation, $\mathrm{Nr} 2 \mathrm{f}$ homologs are necessary for copulation control in nematodes [71] and heart vessel specification in flies [23, 24]. Furthermore, the recent work with the Mediterranean sea urchin suggests that it is required for 
the development of mesendodermal derivatives [67]. The functions of $N r 2 f 1$ and $N r 2 f 2$ genes have been intensely investigated in vertebrate models and they are required for proper human development [22, 31, 72]. Both expression and functional analysis of $N r 2 f 1$ and $N r 2 f 2$ genes in vertebrates show that they have acquired distinct developmental roles during evolution. Following overlapping expression early in mouse embryos, murine $N r 2 f 1$ and $N r 2 f 2$ become predominantly expressed in neural and mesendodermal tissues, respectively [21, 22]. Analysis of these $N r 2 f$ genes in mice and zebrafish support the functional divergence of these proteins. Murine Nr2f1 KOs have glial differentiation defects [73], while $N r 2 f 2$ is required for proper development of many mesendodermal-derived tissues, including atrial chamber and arterialvenous differentiation [40,74]. Intriguingly, mouse Nr2f2 and zebrafish $n r 2 f 1 a$ are functional homologs with respect to heart development, as both are required for atrial differentiation [75], further supporting the common evolutionary origins of these paralogs. While zebrafish $n r 2 f 2$ is not required for early atrial or vein development [29], NR2F1 and NR2F2 TFs do appear to have redundant requirements, for instance promoting atrial cardiomyocyte differentiation in human embryonic stem cells [76, 77]. It is interesting that the single Nr2f1/2/5/6 (svp/Nr2f3) homolog of flies is also required for dorsal vessel (heart) development [23]. However, if these similar roles in mesodermally-derived heart tissues reflect homologous requirements within Bilateria for cardiac differentiation requires functional studies from many additional model organisms [67]. With respect to analysis of the expansion of $N r 2 f 1$ and $N r 2 f 2$ Ohnologs in teleosts, Nr2f1b actually has been lost in the majority of surveyed teleosts. $N r 2 f 1 b$ zebrafish mutants are viable [78] and surprisingly do not exhibit redundancy with nr2f1a in atrial cardiomyocyte differentiation [29], but do exhibit some redundancy with multiple other $\mathrm{Nr} 2 \mathrm{f}$ genes in neural crest cells that promote jaw development [78]. Virtually all the analyzed gnathostome genomes have a single Nr2f2 gene, excluding the teleosts $S$. formosus (2) and $S$. salar (3), implying there may be some dosage sensitivity that favors the retention of single orthologs in gnathostomes.

With respect to the function of $N r 2 f 5$ and $N r 2 f 6$ genes, zebrafish $n r 2 f 5$ mutants are viable, yet like zebrafish $n r 2 f 1 b$ mutants they function redundantly with other $n r 2 f$ genes for proper upper-jaw development [78]. While expression and functional analysis from other organisms that have retained Nr2f5 (coelacanth, spotted gar, and frog) may provide insights into conservation of $N r 2 f 5$ orthologs, the independent loss of $N r 2 f 5$ genes in multiple vertebrate lineages, as well as the lack of overt requirements alone in zebrafish, suggests that $\mathrm{Nr} 2 \mathrm{f} 5$ orthologs likely have retained minimal developmental requirements and its loss can be tolerated. Murine Nr2f6 KO mice have forebrain defects. Specifically, these mutants show a loss of neurons that regulate the circadian clock genes [79]. However, $\mathrm{Nr} 2 \mathrm{f6}$ also has a critical role in lymphocyte differentiation and T-cell mediated tumor surveillance, suggesting requirements in mesodermally-derived tissues and neofunctionalization in adaptive immunity [80, 81]. Altogether, minimally, expression and functional data support requirements for $\mathrm{Nr} 2 \mathrm{fs}$ in all three germ layers of Bilateria. However, the conservation of these requirements and if they reflect homologous roles in the different germ layers throughout Bilateria is not yet as clear.

In examining the evolution of the Nr2f TFs, it is also worthwhile to note that in earlybranching eumetazoans through invertebrate chordates and gnathostomes there is conserved responsiveness to retinoic acid (RA) signaling [82], a critical molecule involved early patterning of vertebrate embryos [83-85], implying this relationship may form the core of an ancient gene regulatory network. $N r 2 f$ genes from placozoans [58] and the invertebrate chordates Ciona and amphioxus are all RA-responsive [11, 64]. Furthermore, in vertebrates, where the earliest requirement for RA is posteriorization of the embryo [86], virtually all the $\mathrm{Nr} 2 \mathrm{f}$ genes have been shown to be responsive to RA signaling in developmental contexts involving all three germ layers. Specifically, RA signaling has been shown to positively regulate all the $\mathrm{Nr} 2 \mathrm{fs}$ 
in zebrafish in the developing zebrafish endoderm [87], the CNS [68], and anterior lateral plate mesoderm (ALPM) [29]. RA signaling also positively regulates $N r 2 f 1, N r 2 f 2$ and $N r 2 f 6$ in mice $[88,89]$, and NR2F1 and NR2F2 in humans [90, 91]. Nr2fs can inhibit RA signaling in some contexts, suggesting it may form a negative feedback loop. One role Nr2fs may play is through direct competition with retinoic acid receptors (RARs) in binding retinoic acid response elements (RAREs) [21]. Moreover, it has been shown that the cnidarian Nr2f1/2/5/6c possesses the ability to inhibit RA signaling in in vitro signaling assays [14]. Thus, the responsiveness of the Nr2f family to RA may have evolved very early and has been highly maintained through the diversification of multiple vertebrate $\mathrm{Nr} 2 \mathrm{f}$ genes, implying there is high selection to maintain this relationship.

\section{Conclusions}

Overall, our evolutionary assessment sheds new light on the events that have shaped the extant $N r 2 f$ family in Metazoa. The phylogenetic analysis defines the individual $N r 2 f$ subfamilies and their relationships across metazoan phyla, which complements available expression and functional data presently supporting an origin of their requirements in the development of neural tissue. Interestingly, the functions of $\mathrm{Nr} 2 \mathrm{f}$ proteins are found to regulate development of all germ layers of Bilateria. The detailed evolutionary understanding of the $N r 2 f$ gene family we now have will allow us to infer more meaningful conclusions about the origins and conserved requirements of $\mathrm{Nr} 2 \mathrm{f}$ genes in normal metazoan development and their role in sculpting diverse body plans.

\section{Methods}

\section{Ethics statement}

Ethical approval is not required. No animals were used in this study.

\section{Genome database searches and phylogenetic reconstruction}

Homo sapiens NR2F protein sequences were employed as queries in BLASTp and tBLASTn in genome databases of selected species (NCBI, Ensembl, Ensembl Metazoa, SkateBase [92], ANISEED [93]). The entire dataset of protein sequences for domain architecture was analyzed by using the domain database provided by Expasy, named PROSITE [94] and then, manually annotated. All the surveyed sequences were verified to be Nr2f proteins through analysis of DBDs and LBDs (S6 File). The analysis was weighted with 30 species from agnathans to primates to take into account the impact of multiple WGDs in vertebrates [41, 42] and in teleosts $[17,18]$. Orthology of the $N r 2 f$ members was initially assessed by using a reciprocal best blast hit (RBBH) approach employing default parameters and corroborated by phylogenetic analyses. Protein alignment for phylogeny was generated using L-INS-i (accurate; for alignment of $<200$ sequences) on MAFFT [95, 96] (S7 File). The phylogenetic reconstruction of Fig 2 was performed on the entire protein sequences and based on maximum-likelihood (ML) inferences calculated with PhyML 3.0 [97], employing automatic Akaike Information Criterion (AIC) by Smart Model Substitution (SMS) [98], which selected the JTT + G+F model employing discrete gamma distribution in categories. All parameters (gamma shape $=0.7$; proportion of invariants (fixed) $=0.000$ ) were established from the dataset. Branch support was provided by aLRT [99]. The phylogeny of S1 Fig was carried out employing Bayesian Information Criterion (BIC) by SMS, which sorted the JTT $+\mathrm{G}+\mathrm{F}$ model using discrete gamma distribution in categories. All parameters (gamma shape $=0.7$; proportion of invariants $($ fixed $)=0.000$ ) were established from the dataset, with branch support calculated employing aBayes method [100]. 
Accession numbers and protein sequences used for phylogenetic tree reconstructions are provided in S1, S6, and S7 Files, while those excluded for their divergence are listed in S2 File. Common and Latin names for species used in this study are listed in S8 File.

\section{Analysis of intron/exon structures and phases}

Gene structures were deduced after merging the genomic sequences with ESTs when available, as previously described [50-52]. Introns were classified as phase 0 , phase 1 , and phase 2 , according to their positions with respect to the protein-reading frame. The amino-acid residues with the conserved introns were manually mapped on a ClustalX alignment [101] of selected Nr2f proteins (S9 File).

\section{Evaluation of synteny}

We evaluated the presence/absence of synteny examining the chromosomes on public genome databases (NCBI, Ensembl, Ensembl Metazoa, ANISEED [93]). We verified the existence of duplicates using Genomicus [102] and Vertebrate Ohnologs [103]. The window considered for the locus analyses was twenty flanking genes. Genes that were not conserved were excluded from the analysis. All the genes were represented employing colored rectangles, using the same color for all $\mathrm{Nr} 2 f$ genes (red).

\section{Supporting information}

S1 Fig. Phylogenetic tree of the Nr2f family, using Bayesian Information Criterion (BIC). The same color code as Fig 2 is used. Values at the branches indicate replicates obtained employing the aBayes method.

S2 Fig. Synteny analysis of $N r 2 f 1 / 2 / 5 / 6$ genes found invertebrates. Schematic of limited conservation for $\mathrm{Nr} 2 \mathrm{f1} / 2 / 5 / 6$ loci between the hemichordate S. kowalevskii and amphioxus B. belcheri. Black arrows indicate transcription orientation.

S3 Fig. Unc45-Nr2f gene duplet preservation. Schematic of Unc45-Nr2f duplet conservation in genomes of ascidians (Ciona) and primates. The duplet is absent in other vertebrate models, including zebrafish and mouse.

S4 Fig. Synteny analysis of $\mathbf{N r} \mathbf{f} \mathbf{f} / \mathbf{2}$ genes in agnathans. Schematic of lamprey (P. marinus) $\mathrm{Nr} 2 \mathrm{f1} / 2$ loci with relative chromosomes and available genomic data from the hagfish (E. burgeri). Genomic data could only be obtained for the hagfish $N r 2 f 1 / 2 C$ gene. Same color code of Figs 6-8 is used. Flanking genes are in common with gnathostomes, with $A r r d c 2$ and $A r r d c 3$ (green) that form a conserved duplet with $N r 2 f 1 / 2 B$ and $N r 2 f 1 / 2 C$. Nr2f1/2C is adjacent to Fam172a in both lamprey and hagfish. Arrows indicate transcription orientation. (TIF)

S1 File. List of all protein sequences employed in Nr2f phylogenetic tree with accession numbers.

S2 File. List of protein sequences excluded from Nr2f phylogenetic tree due to their high degree of divergence.

(TXT) 
S3 File. List of examined species whose genomes lacked $N r 2 f 5$ with their common names, Latin names, and phyla.

(XLSX)

S4 File. Intron/Exon structure of $N r 2 f$ genes in Metazoa. Alignment of specific and conserved intron/exon boundaries within the Zinc finger motifs of DBD (underlined) and LBDs (red). The intron phases have been depicted using color code: Phase 0 (yellow), Phase 1 (green), Phase 2 (turquoise).

(DOCX)

S5 File. Sequences of additional salmonid and cichlid Nr2f5 proteins. (TXT)

S6 File. Nr2f domain architectures during metazoan evolution. Sequences used in analysis with DBDs (yellow) and LBDs (green) domains in metazoan Nr2f proteins indicated. the Zinc-finger motifs within the DBDs are underlined.

(DOCX)

S7 File. MAFFT alignment of protein sequences used for phylogenetic analysis of Fig 2 and S1 Fig.

S8 File. List of species used for our evolutionary analyses with their common names, Latin names, and phyla.

(XLSX)

S9 File. Selected Nr2f transcripts and translations used for analysis with the positions and phases of intron/exon boundaries indicated.

(DOCX)

\section{Author Contributions}

Conceptualization: Ugo Coppola, Joshua S. Waxman.

Data curation: Ugo Coppola.

Formal analysis: Ugo Coppola.

Funding acquisition: Joshua S. Waxman.

Investigation: Ugo Coppola.

Methodology: Ugo Coppola.

Supervision: Joshua S. Waxman.

Validation: Ugo Coppola.

Visualization: Joshua S. Waxman.

Writing - original draft: Ugo Coppola, Joshua S. Waxman.

Writing - review \& editing: Ugo Coppola, Joshua S. Waxman.

\section{References}

1. Laudet $\mathrm{V}$. Evolution of the nuclear receptor superfamily: early diversification from an ancestral orphan receptor. J Mol Endocrinol. 1997; 19: 207-226. https://doi.org/10.1677/jme.0.0190207 PMID: 9460643 
2. Escriva H, Safi R, Hänni C, Langlois $M C$, Saumitou-Laprade $P$, Stehelin D, et al. Ligand binding was acquired during evolution of nuclear receptors. Proc Natl Acad Sci U S A. 1997; 94: 6803-6808. https://doi.org/10.1073/pnas.94.13.6803 PMID: 9192646

3. Escriva H, Bertrand S, Laudet $\mathrm{V}$. The evolution of the nuclear receptor superfamily. Essays in Biochemistry. 2004. pp. 11-26. https://doi.org/10.1042/bse0400011 PMID: 15242336

4. Mangelsdorf DJ, Evans RM. The RXR heterodimers and orphan receptors. Cell. 1995. pp. 841-850. https://doi.org/10.1016/0092-8674(95)90200-7 PMID: 8521508

5. Pastorcic M, Wang H, Elbrecht A, Tsai SY, Tsai MJ, O'Malley BW. Control of transcription initiation in vitro requires binding of a transcription factor to the distal promoter of the ovalbumin gene. Molecular and Cellular Biology. 1986. pp. 2784-2791. https://doi.org/10.1128/mcb.6.8.2784-2791.1986 PMID: 3785213

6. Sagami I, Tsai SY, Wang H, Tsai MJ, O'Malley BW. Identification of two factors required for transcription of the ovalbumin gene. Mol Cell Biol. 1986; 6: 4259-4267. https://doi.org/10.1128/mcb.6.12.42594267.1986 PMID: 3796602

7. Wang LH, Tsai SY, Cook RG, Beattie WG, Tsai MJ, O'Malley BW. COUP transcription factor is a member of the steroid receptor superfamily. Nature. 1989; 340: 163-166. https://doi.org/10.1038/ 340163a0 PMID: 2739739

8. Mlodzik M, Hiromi Y, Weber U, Goodman CS, Rubin GM. The Drosophila seven-up gene, a member of the steroid receptor gene superfamily, controls photoreceptor cell fates. Cell. 1990; 60: 211-224. https://doi.org/10.1016/0092-8674(90)90737-y PMID: 2105166

9. Chan SM, Xu N, Niemeyer CC, Bone JR, Flytzanis CN. SpCOUP-TF: a sea urchin member of the steroid/thyroid hormone receptor family. Proc Natl Acad Sci U S A. 1992; 89: 10568-10572. https://doi. org/10.1073/pnas.89.22.10568 PMID: 1438252

10. Langlois MC, Vanacker JM, Holland ND, Escriva H, Queva C, Laudet V, et al. Amphicoup-TF, a nuclear orphan receptor of the lancelet Branchiostoma floridae, is implicated in retinoic acid signalling pathways. Dev Genes Evol. 2000; 210: 471-482. https://doi.org/10.1007/s004270000087 PMID: 11180796

11. Ishibashi T, Usami T, Fujie M, Azumi K, Satoh N, Fujiwara S. Oligonucleotide-based microarray analysis of retinoic acid target genes in the protochordate, Ciona intestinalis. Dev Dyn. 2005; 233: 15711578. https://doi.org/10.1002/dvdy.20486 PMID: 15977162

12. Duffy DJ, Frank U. Modulation of COUP-TF expression in a cnidarian by ectopic Wnt signalling and allorecognition. PLoS One. 2011; 6: e19443. https://doi.org/10.1371/journal.pone.0019443 PMID: 21552541

13. Beinsteiner B, Markov GV, Erb S, Chebaro Y, McEwen AG, Cianférani S, et al. A structural signature motif enlightens the origin and diversification of nuclear receptors. PLoS Genet. 2021; 17: e1009492. https://doi.org/10.1371/journal.pgen.1009492 PMID: 33882063

14. Gauchat D, Escriva H, Miljkovic-Licina M, Chera S, Langlois M-C, Begue A, et al. The orphan COUPTF nuclear receptors are markers for neurogenesis from cnidarians to vertebrates. Dev Biol. 2004; 275: 104-123. https://doi.org/10.1016/j.ydbio.2004.07.037 PMID: 15464576

15. Reitzel AM, Tarrant AM. Nuclear receptor complement of the cnidarian Nematostella vectensis: phylogenetic relationships and developmental expression patterns. BMC Evolutionary Biology. 2009. p. 230. https://doi.org/10.1186/1471-2148-9-230 PMID: 19744329

16. Bertrand S, Thisse B, Tavares R, Sachs L, Chaumot A, Bardet P-L, et al. Unexpected novel relational links uncovered by extensive developmental profiling of nuclear receptor expression. PLoS Genet. 2007; 3: e188. https://doi.org/10.1371/journal.pgen.0030188 PMID: 17997606

17. Taylor JS. Genome Duplication, a Trait Shared by 22,000 Species of Ray-Finned Fish. Genome Research. 2003. pp. 382-390. https://doi.org/10.1101/gr.640303 PMID: 12618368

18. Jaillon O, Aury J-M, Brunet F, Petit J-L, Stange-Thomann N, Mauceli E, et al. Genome duplication in the teleost fish Tetraodon nigroviridis reveals the early vertebrate proto-karyotype. Nature. 2004; 431 : 946-957. https://doi.org/10.1038/nature03025 PMID: 15496914

19. Giguère V. Orphan nuclear receptors: from gene to function. Endocr Rev. 1999; 20: 689-725. https:// doi.org/10.1210/edrv.20.5.0378 PMID: 10529899

20. Germain P, Staels B, Dacquet C, Spedding M, Laudet V. Overview of nomenclature of nuclear receptors. Pharmacol Rev. 2006; 58: 685-704. https://doi.org/10.1124/pr.58.4.2 PMID: 17132848

21. Tsai SY, Tsai MJ. Chick ovalbumin upstream promoter-transcription factors (COUP-TFs): coming of age. Endocr Rev. 1997; 18: 229-240. https://doi.org/10.1210/edrv.18.2.0294 PMID: 9101138

22. Pereira FA, Tsai MJ, Tsai SY. COUP-TF orphan nuclear receptors in development and differentiation. Cell Mol Life Sci. 2000; 57: 1388-1398. https://doi.org/10.1007/PL00000624 PMID: 11078018 
23. Lo PC, Frasch M. A role for the COUP-TF-related gene seven-up in the diversification of cardioblast identities in the dorsal vessel of Drosophila. Mech Dev. 2001; 104: 49-60. https://doi.org/10.1016/ s0925-4773(01)00361-6 PMID: 11404079

24. Ryan KM, Hendren JD, Helander LA, Cripps RM. The NK homeodomain transcription factor Tinman is a direct activator of seven-up in the Drosophila dorsal vessel. Dev Biol. 2007; 302: 694-702. https:// doi.org/10.1016/j.ydbio.2006.10.025 PMID: 17098220

25. Qiu Y, Tsai SY, Tsai M-J. COUP-TF an orphan member of the steroid/thyroid hormone receptor superfamily. Trends in Endocrinology \& Metabolism. 1994. pp. 234-239. https://doi.org/10.1016/1043-2760 (94)p3081-h PMID: 18407213

26. Pereira FA, Qiu Y, Tsai MJ, Tsai SY. Chicken ovalbumin upstream promoter transcription factor (COUP-TF): expression during mouse embryogenesis. J Steroid Biochem Mol Biol. 1995; 53: 503508. https://doi.org/10.1016/0960-0760(95)00097-j PMID: 7626501

27. Pereira FA, Qiu Y, Zhou G, Tsai M-J, Tsai SY. The orphan nuclear receptor COUP-TFII is required for angiogenesis and heart development. Genes \& Development. 1999. pp. 1037-1049. https://doi.org/ 10.1101/gad.13.8.1037 PMID: 10215630

28. Xie X, Qin J, Lin S-H, Tsai SY, Tsai M-J. Nuclear receptor chicken ovalbumin upstream promoter-transcription factor II (COUP-TFII) modulates mesenchymal cell commitment and differentiation. Proc Natl Acad Sci U S A. 2011; 108: 14843-14848. https://doi.org/10.1073/pnas.1110236108 PMID: 21873211

29. Dohn TE, Ravisankar P, Tirera FT, Martin KE, Gafranek JT, Duong TB, et al. Nr2f-dependent allocation of ventricular cardiomyocyte and pharyngeal muscle progenitors. PLoS Genet. 2019; 15: e1007962. https://doi.org/10.1371/journal.pgen.1007962 PMID: 30721228

30. Kliewer SA, Umesono K, Noonan DJ, Heyman RA, Evans RM. Convergence of 9-cis retinoic acid and peroxisome proliferator signalling pathways through heterodimer formation of their receptors. Nature. 1992; 358: 771-774. https://doi.org/10.1038/358771a0 PMID: 1324435

31. Tang K, Tsai SY, Tsai M-J. COUP-TFs and eye development. Biochim Biophys Acta. 2015; 1849 : 201-209. https://doi.org/10.1016/j.bbagrm.2014.05.022 PMID: 24878540

32. Cooney AJ, Tsai SY, O'Malley BW. Chicken ovalbumin upstream promoter transcription factor (COUP-TF) dimers bind to different GGTCA response elements, allowing COUP-TF to repress hormonal . ... Molecular and cellular. 1992. https://mcb.asm.org/content/12/9/4153.short

33. Schräder M, Danielsson C, Wiesenberg I, Carlberg C. Identification of Natural Monomeric Response Elements of the Nuclear Receptor RZR/ROR. THEY ALSO BIND COUP-TF HOMODIMERS. Journal of Biological Chemistry. 1996. pp. 19732-19736. https://doi.org/10.1074/jbc.271.33.19732 PMID: 8702678

34. Pipaón C, Tsai SY, Tsai MJ. COUP-TF upregulates NGFI-A gene expression through an Sp1 binding site. Mol Cell Biol. 1999; 19: 2734-2745. https://doi.org/10.1128/MCB.19.4.2734 PMID: 10082539

35. Tran P, Zhang XK, Salbert G, Hermann T, Lehmann JM, Pfahl M. COUP orphan receptors are negative regulators of retinoic acid response pathways. Mol Cell Biol. 1992; 12: 4666-4676. https://doi.org/ 10.1128/mcb.12.10.4666-4676.1992 PMID: 1328857

36. Tang LS, Alger HM, Pereira FA. COUP-TFI controls Notch regulation of hair cell and support cell differentiation. Development. 2006; 133: 3683-3693. https://doi.org/10.1242/dev.02536 PMID: 16914494

37. Montemayor C, Montemayor OA, Ridgeway A, Lin F, Wheeler DA, Pletcher SD, et al. Genome-wide analysis of binding sites and direct target genes of the orphan nuclear receptor NR2F1/COUP-TFI. PLoS One. 2010; 5: e8910. https://doi.org/10.1371/journal.pone.0008910 PMID: 20111703

38. Chiang DY, Cuthbertson DW, Ruiz FR, Li N, Pereira FA. A coregulatory network of NR2F1 and microRNA-140. PLoS One. 2013; 8: e83358. https://doi.org/10.1371/journal.pone.0083358 PMID: 24349493

39. Okamura M, Kudo H, Wakabayashi K-I, Tanaka T, Nonaka A, Uchida A, et al. COUP-TFIl acts downstream of Wnt/ -catenin signal to silence PPAR gene expression and repress adipogenesis. Proceedings of the National Academy of Sciences. 2009. pp. 5819-5824. https://doi.org/10.1073/pnas. 0901676106 PMID: 19307559

40. Wu S-P, Cheng C-M, Lanz RB, Wang T, Respress JL, Ather S, et al. Atrial identity is determined by a COUP-TFII regulatory network. Dev Cell. 2013; 25: 417-426. https://doi.org/10.1016/j.devcel.2013. 04.017 PMID: 23725765

41. Abi-Rached L, Gilles $A$, Shiina $T$, Pontarotti $P$, Inoko $H$. Evidence of en bloc duplication in vertebrate genomes. Nat Genet. 2002; 31: 100-105. https://doi.org/10.1038/ng855 PMID: 11967531

42. Dehal $P$, Boore JL. Two rounds of whole genome duplication in the ancestral vertebrate. PLoS Biol. 2005; 3: e314. https://doi.org/10.1371/journal.pbio.0030314 PMID: 16128622 
43. van der Wees J, Matharu PJ, de Roos K, Destre'e OHJ, Godsave SF, Durston AJ, et al. Developmental expression and differential regulation by retinoic acid ofXenopus COUP-TF-A andCOUP-TF-B. Mech Dev. 1996; 54: 173-184. https://doi.org/10.1016/0925-4773(95)00471-8 PMID: 8652410

44. Bertrand S, Brunet FG, Escriva H, Parmentier G, Laudet V, Robinson-Rechavi M. Evolutionary genomics of nuclear receptors: from twenty-five ancestral genes to derived endocrine systems. Mol Biol Evol. 2004; 21: 1923-1937. https://doi.org/10.1093/molbev/msh200 PMID: 15229292

45. Bridgham JT, Eick GN, Larroux C, Deshpande K, Harms MJ, Gauthier MEA, et al. Protein evolution by molecular tinkering: diversification of the nuclear receptor superfamily from a ligand-dependent ancestor. PLoS Biol. 2010; 8. https://doi.org/10.1371/journal.pbio.1000497 PMID: 20957188

46. Read TD, Petit RA 3rd, Joseph SJ, Alam MT, Weil MR, Ahmad M, et al. Draft sequencing and assembly of the genome of the world's largest fish, the whale shark: Rhincodon typus Smith 1828. BMC Genomics. 2017; 18: 532. https://doi.org/10.1186/s12864-017-3926-9 PMID: 28709399

47. Marra NJ, Stanhope MJ, Jue NK, Wang M, Sun Q, Pavinski Bitar P, et al. White shark genome reveals ancient elasmobranch adaptations associated with wound healing and the maintenance of genome stability. Proc Natl Acad Sci U S A. 2019; 116: 4446-4455. https://doi.org/10.1073/pnas.1819778116 PMID: 30782839

48. Fonseca E, Machado AM, Vilas-Arrondo N, Gomes-dos-Santos A, Veríssimo A, Esteves P, et al. Cartilaginous fishes offer unique insights into the evolution of the nuclear receptor gene repertoire in gnathostomes. General and Comparative Endocrinology. 2020. p. 113527. https://doi.org/10.1016/j. ygcen.2020.113527 PMID: 32526329

49. Lien S, Koop BF, Sandve SR, Miller JR, Kent MP, Nome T, et al. The Atlantic salmon genome provides insights into rediploidization. Nature. 2016; 533: 200-205. https://doi.org/10.1038/nature17164 PMID: 27088604

50. D’Aniello S, Irimia M, Maeso I, Pascual-Anaya J, Jiménez-Delgado S, Bertrand S, et al. Gene expansion and retention leads to a diverse tyrosine kinase superfamily in amphioxus. Mol Biol Evol. 2008; 25: 1841-1854. https://doi.org/10.1093/molbev/msn132 PMID: 18550616

51. Roy SW, Irimia M. When good transcripts go bad: artifactual RT-PCR "splicing" and genome analysis. Bioessays. 2008; 30: 601-605. https://doi.org/10.1002/bies.20749 PMID: 18478540

52. Coppola U, Ristoratore F, Albalat R, D'Aniello S. The evolutionary landscape of the Rab family in chordates. Cell Mol Life Sci. 2019; 76: 4117-4130. https://doi.org/10.1007/s00018-019-03103-7 PMID: 31028425

53. Putnam NH, Butts T, Ferrier DEK, Furlong RF, Hellsten U, Kawashima T, et al. The amphioxus genome and the evolution of the chordate karyotype. Nature. 2008; 453: 1064-1071. https://doi.org/ 10.1038/nature06967 PMID: 18563158

54. Simakov O, Kawashima T, Marlétaz F, Jenkins J, Koyanagi R, Mitros T, et al. Hemichordate genomes and deuterostome origins. Nature. 2015; 527: 459-465. https://doi.org/10.1038/nature16150 PMID: 26580012

55. Delsuc F, Brinkmann $H$, Chourrout $D$, Philippe $H$. Tunicates and not cephalochordates are the closest living relatives of vertebrates. Nature. 2006; 439: 965-968. https://doi.org/10.1038/nature04336 PMID: 16495997

56. Simakov O, Marlétaz F, Yue J-X, O'Connell B, Jenkins J, Brandt A, et al. Deeply conserved synteny resolves early events in vertebrate evolution. Nat Ecol Evol. 2020; 4: 820-830. https://doi.org/10. 1038/s41559-020-1156-z PMID: 32313176

57. Li J, Bian C, Hu Y, Mu X, Shen X, Ravi V, et al. A chromosome-level genome assembly of the Asian arowana, Scleropages formosus. Scientific Data. 2016. https://doi.org/10.1038/sdata.2016.105 PMID: 27922628

58. Novotný JP, Chughtai AA, Kostrouchová M, Kostrouchová V, Kostrouch D, Kaššák F, et al. Trichoplax adhaerens reveals a network of nuclear receptors sensitive to 9-cis-retinoic acid at the base of metazoan evolution. PeerJ. 2017. p. e3789. https://doi.org/10.7717/peerj.3789 PMID: 28975052

59. Martí-Solans J, Belyaeva OV, Torres-Aguila NP, Kedishvili NY, Albalat R, Cañestro C. Coelimination and Survival in Gene Network Evolution: Dismantling the RA-Signaling in a Chordate. Mol Biol Evol. 2016; 33: 2401-2416. https://doi.org/10.1093/molbev/msw118 PMID: 27406791

60. Coppola U, Kamal AK, Stolfi A, Ristoratore F. The Cis-Regulatory Code for Kelch-like 21/30 Specific Expression in Ciona robusta Sensory Organs. Front Cell Dev Biol. 2020; 8: 569601. https://doi.org/10. 3389/fcell.2020.569601 PMID: 33043001

61. Guérin A, d'Aubenton-Carafa Y, Marrakchi E, Da Silva C, Wincker P, Mazan S, et al. Neurodevelopment genes in lampreys reveal trends for forebrain evolution in craniates. PLoS One. 2009; 4: e5374 https://doi.org/10.1371/journal.pone.0005374 PMID: 19399187 
62. Kanai MI, Okabe M, Hiromi Y. seven-up Controls Switching of Transcription Factors that Specify Temporal Identities of Drosophila Neuroblasts. Developmental Cell. 2005. pp. 203-213. https://doi.org/10. 1016/j.devcel.2004.12.014 PMID: 15691762

63. Zhou HM, Walthall WW. UNC-55, an orphan nuclear hormone receptor, orchestrates synaptic specificity among two classes of motor neurons in Caenorhabditis elegans. J Neurosci. 1998; 18: 1043810444. https://doi.org/10.1523/JNEUROSCI.18-24-10438.1998 PMID: 9852581

64. Escriva H, Holland ND, Gronemeyer H, Laudet V, Holland LZ. The retinoic acid signaling pathway regulates anterior/posterior patterning in the nerve cord and pharynx of amphioxus, a chordate lacking neural crest. Development. 2002; 129: 2905-2916. PMID: 12050138

65. Devine C, Hinman VF, Degnan BM. Evolution and developmental expression of nuclear receptor genes in the ascidian Herdmania. Int J Dev Biol. 2002; 46: 687-692. PMID: 12141458

66. Kalampoki LG, Flytzanis CN. Cis-regulatory control of the nuclear receptor Coup-TF gene in the sea urchin Paracentrotus lividus embryo. PLoS One. 2014; 9: e109274. https://doi.org/10.1371/journal. pone.0109274 PMID: 25386650

67. Tsironis I, Paganos P, Gouvi G, Tsimpos P, Stamopoulou A, Arnone MI, et al. Coup-TF: A maternal factor essential for differentiation along the embryonic axes in the sea urchin Paracentrotus lividus. Dev Biol. 2021. https://doi.org/10.1016/j.ydbio.2020.12.012 PMID: 33484706

68. Love CE, Prince VE. Expression and retinoic acid regulation of the zebrafish nr2f orphan nuclear receptor genes. Dev Dyn. 2012; 241: 1603-1615. https://doi.org/10.1002/dvdy.23838 PMID: 22836912

69. Fjose A, Nornes S, Weber U, Mlodzik M. Functional conservation of vertebrate seven-up related genes in neurogenesis and eye development. EMBO J. 1993; 12: 1403-1414. PMID: 8467797

70. Sousounis K, Looso M, Maki N, Ivester CJ, Braun T, Tsonis PA. Transcriptome Analysis of Newt Lens Regeneration Reveals Distinct Gradients in Gene Expression Patterns. PLoS ONE. 2013. p. e61445. https://doi.org/10.1371/journal.pone.0061445 PMID: 23613853

71. Shan G, Walthall WW. Copulation in C. elegans males requires a nuclear hormone receptor. Dev Biol. 2008; 322: 11-20. https://doi.org/10.1016/j.ydbio.2008.06.034 PMID: 18652814

72. Yang X, Feng S, Tang K. COUP-TF Genes, Human Diseases, and the Development of the Central Nervous System in Murine Models. Curr Top Dev Biol. 2017; 125: 275-301. https://doi.org/10.1016/ bs.ctdb.2016.12.002 PMID: 28527575

73. Yamaguchi H, Zhou C, Lin S-C, Durand B, Tsai SY, Tsai M-J. The nuclear orphan receptor COUP-TFI is important for differentiation of oligodendrocytes. Dev Biol. 2004; 266: 238-251. https://doi.org/10. 1016/j.ydbio.2003.10.038 PMID: 14738874

74. Cui X, Lu YW, Lee V, Kim D, Dorsey T, Wang Q, et al. Venous Endothelial Marker COUP-TFII Regulates the Distinct Pathologic Potentials of Adult Arteries and Veins. Sci Rep. 2015; 5: 16193. https:// doi.org/10.1038/srep16193 PMID: 26537113

75. Duong TB, Ravisankar P, Song YC, Gafranek JT, Rydeen AB, Dohn TE, et al. Nr2f1a balances atrial chamber and atrioventricular canal size via BMP signaling-independent and -dependent mechanisms. Dev Biol. 2018; 434: 7-14. https://doi.org/10.1016/j.ydbio.2017.11.010 PMID: 29157563

76. Devalla HD, Schwach V, Ford JW, Milnes JT, El-Haou S, Jackson C, et al. Atrial-like cardiomyocytes from human pluripotent stem cells are a robust preclinical model for assessing atrial-selective pharmacology. EMBO Mol Med. 2015; 7: 394-410. https://doi.org/10.15252/emmm.201404757 PMID: 25700171

77. Schwach V, Verkerk AO, Mol M, Monshouwer-Kloots JJ, Devalla HD, Orlova VV, et al. A COUP-TFII Human Embryonic Stem Cell Reporter Line to Identify and Select Atrial Cardiomyocytes. Stem Cell Reports. 2017; 9: 1765-1779. https://doi.org/10.1016/j.stemcr.2017.10.024 PMID: 29173897

78. Barske L, Rataud P, Behizad K, Del Rio L, Cox SG, Gage Crump J. Essential Role of Nr2f Nuclear Receptors in Patterning the Vertebrate Upper Jaw. Developmental Cell. 2018. pp. 337-347.e5. https://doi.org/10.1016/j.devcel.2017.12.022 PMID: 29358039

79. Warnecke M, Oster H, Revelli JP. Abnormal development of the locus coeruleus in Ear2 (Nr2f6)-deficient mice impairs the functionality of the forebrain clock and affects nociception. Genes. 2005. http:// genesdev.cshlp.org/content/19/5/614.short

80. Ichim CV, Dervovic D, Zuniga-Pflucker JC, Wells RA. The Orphan Nuclear Receptor NR2F6 Is a Novel Negative Regulator of T-Cell Development. Blood. 2009. pp. 915-915.

81. Hermann-Kleiter N, Baier G. Orphan nuclear receptor NR2F6 acts as an essential gatekeeper of Th17 CD4 T cell effector functions. Cell Communication and Signaling. 2014. p. 38. https://doi.org/10.1186/ 1478-811X-12-38 PMID: 24919548

82. Campo-Paysaa F, Marlétaz F, Laudet V, Schubert M. Retinoic acid signaling in development: tissuespecific functions and evolutionary origins. Genesis. 2008; 46: 640-656. https://doi.org/10.1002/dvg. 20444 PMID: 19003929 
83. Stafford D, Hornbruch A, Mueller PR, Prince VE. A conserved role for retinoid signaling in vertebrate pancreas development. Dev Genes Evol. 2004; 214: 432-441. https://doi.org/10.1007/s00427-0040420-6 PMID: 15322880

84. Perl E, Waxman JS. Reiterative Mechanisms of Retinoic Acid Signaling during Vertebrate Heart Development. J Dev Biol. 2019; 7. https://doi.org/10.3390/jdb7020011 PMID: 31151214

85. Bedois AMH, Parker HJ, Krumlauf R. Retinoic Acid Signaling in Vertebrate Hindbrain Segmentation: Evolution and Diversification. Diversity. 2021; 13: 398.

86. Duester G. Retinoic acid synthesis and signaling during early organogenesis. Cell. 2008; 134: $921-$ 931. https://doi.org/10.1016/j.cell.2008.09.002 PMID: 18805086

87. Kinkel MD, Prince VE. On the diabetic menu: zebrafish as a model for pancreas development and function. Bioessays. 2009; 31: 139-152. https://doi.org/10.1002/bies.200800123 PMID: 19204986

88. Jonk LJ, de Jonge ME, Pals CE, Wissink S, Vervaart JM, Schoorlemmer J, et al. Cloning and expression during development of three murine members of the COUP family of nuclear orphan receptors. Mech Dev. 1994; 47: 81-97. https://doi.org/10.1016/0925-4773(94)90098-1 PMID: 7947324

89. Fjose A, Weber U, Mlodzik M. A novel vertebrate svp-related nuclear receptor is expressed as a step gradient in developing rhombomeres and is affected by retinoic acid. Mech Dev. 1995; 52: 233-246. https://doi.org/10.1016/0925-4773(95)00404-o PMID: 8541212

90. Zaitseva M, Vollenhoven BJ, Rogers PAW. Retinoids regulate genes involved in retinoic acid synthesis and transport in human myometrial and fibroid smooth muscle cells. Hum Reprod. 2008; 23: 10761086. https://doi.org/10.1093/humrep/den083 PMID: 18343808

91. Laursen KB, Mongan NP, Zhuang Y, Ng MM, Benoit YD, Gudas LJ. Polycomb recruitment attenuates retinoic acid-induced transcription of the bivalent NR2F1 gene. Nucleic Acids Res. 2013; 41: 64306443. https://doi.org/10.1093/nar/gkt367 PMID: 23666625

92. Wyffels J, King BL, Vincent J, Chen C, Wu CH, Polson SW. SkateBase, an elasmobranch genome project and collection of molecular resources for chondrichthyan fishes. F1000Res. 2014; 3: 191. https://doi.org/10.12688/f1000research.4996.1 PMID: 25309735

93. Dardaillon J, Dauga D, Simion P, Faure E, Onuma TA, DeBiasse MB, et al. ANISEED 2019: 4D exploration of genetic data for an extended range of tunicates. Nucleic Acids Res. 2020; 48: D668-D675. https://doi.org/10.1093/nar/gkz955 PMID: 31680137

94. de Castro E, Sigrist CJA, Gattiker A, Bulliard V, Langendijk-Genevaux PS, Gasteiger E, et al. ScanProsite: detection of PROSITE signature matches and ProRule-associated functional and structural residues in proteins. Nucleic Acids Res. 2006; 34: W362-5. https://doi.org/10.1093/nar/gkl124 PMID: 16845026

95. Katoh K, Kuma K-I, Toh H, Miyata T. MAFFT version 5: improvement in accuracy of multiple sequence alignment. Nucleic Acids Res. 2005; 33: 511-518. https://doi.org/10.1093/nar/gki198 PMID: 15661851

96. Katoh K, Rozewicki J, Yamada KD. MAFFT online service: multiple sequence alignment, interactive sequence choice and visualization. Brief Bioinform. 2019; 20: 1160-1166. https://doi.org/10.1093/bib/ bbx108 PMID: 28968734

97. Guindon S, Dufayard J-F, Lefort V, Anisimova M, Hordijk W, Gascuel O. New algorithms and methods to estimate maximum-likelihood phylogenies: assessing the performance of PhyML 3.0. Syst Biol. 2010; 59: 307-321. https://doi.org/10.1093/sysbio/syq010 PMID: 20525638

98. Lefort V, Longueville J-E, Gascuel O. SMS: Smart Model Selection in PhyML. Mol Biol Evol. 2017; 34: 2422-2424. https://doi.org/10.1093/molbev/msx149 PMID: 28472384

99. Anisimova M, Gascuel O. Approximate likelihood-ratio test for branches: A fast, accurate, and powerful alternative. Syst Biol. 2006; 55: 539-552. https://doi.org/10.1080/10635150600755453 PMID: 16785212

100. Anisimova M, Gil M, Dufayard J-F, Dessimoz C, Gascuel O. Survey of branch support methods demonstrates accuracy, power, and robustness of fast likelihood-based approximation schemes. Syst Biol. 2011; 60: 685-699. https://doi.org/10.1093/sysbio/syr041 PMID: 21540409

101. Thompson JD, Gibson TJ, Higgins DG. Multiple sequence alignment using ClustalW and ClustalX. Curr Protoc Bioinformatics. 2002; Chapter 2: Unit 2.3. https://doi.org/10.1002/0471250953.bi0203s00 PMID: 18792934

102. Nguyen NTT, Vincens P, Roest Crollius H, Louis A. Genomicus 2018: karyotype evolutionary trees and on-the-fly synteny computing. Nucleic Acids Res. 2018; 46: D816-D822. https://doi.org/10.1093/ nar/gkx1003 PMID: 29087490

103. Singh $\mathrm{PP}$, Isambert $\mathrm{H}$. OHNOLOGS v2: a comprehensive resource for the genes retained from whole genome duplication in vertebrates. Nucleic Acids Res. 2020; 48: D724-D730. https://doi.org/10.1093/ nar/gkz909 PMID: 31612943 